\title{
Has Globalization Really Increased Business Cycle Synchronization?
}




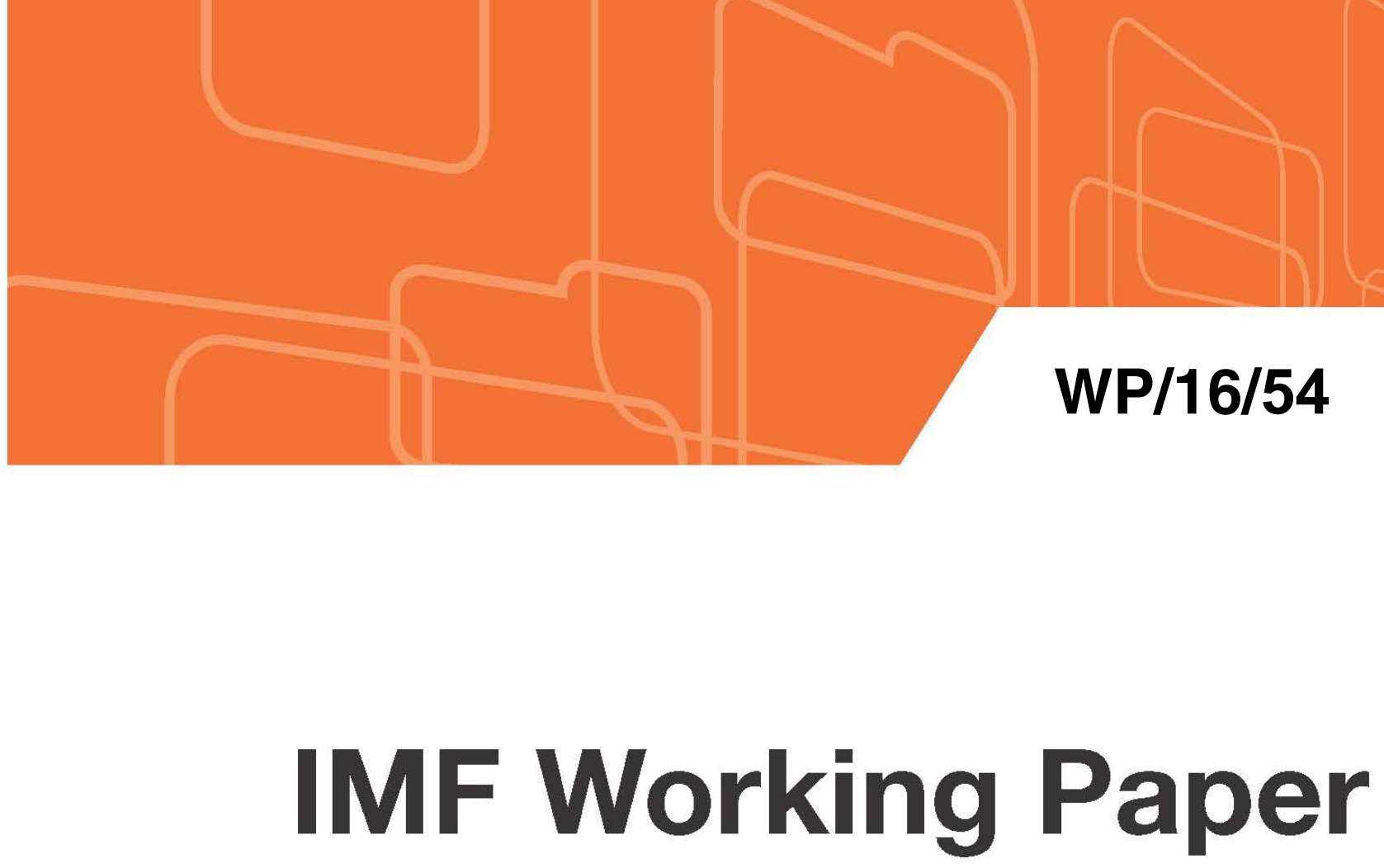

\section{Has Globalization Really Increased Business Cycle Synchronization?}

by Eric Monnet and Damien Puy

IMF Working Papers describe research in progress by the author(s) and are published to elicit comments and to encourage debate. The views expressed in IMF Working

Papers are those of the author(s) and do not necessarily represent the views of the IMF, its Executive Board, or IMF management.

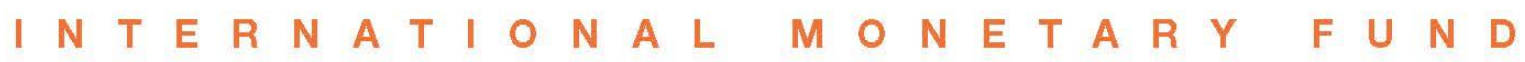




\title{
IMF Working Paper
}

Research Department

\section{Has Globalization Really Increased Business Cycle Synchronization? \\ Prepared by Eric Monnet and Damien Puy ${ }^{1}$ \\ Authorized for distribution by Giovanni Dell’Ariccia}

March 2016

IMF Working Papers describe research in progress by the author(s) and are published to elicit comments and to encourage debate. The views expressed in IMF Working Papers are those of the author(s) and do not necessarily represent the views of the IMF, its Executive Board, or IMF

management.

\begin{abstract}
This paper assesses the strength of business cycle synchronization between 1950 and 2014 in a sample of 21 countries using a new quarterly dataset based on IMF archival data. Contrary to the common wisdom, we find that the globalization period is not associated with more output synchronization at the global level. The world business cycle was as strong during Bretton Woods (1950-1971) than during the Globalization period (1984-2006). Although globalization did not affect the average level of co-movement, trade and financial integration strongly affect the way countries co-move with the rest of the world. We find that financial integration de-synchronizes national outputs from the world cycle, although the magnitude of this effect depends crucially on the type of shocks hitting the world economy. This de-synchronizing effect has offset the synchronizing impact of other forces, such as increased trade integration.
\end{abstract}

JEL Classification Numbers: E32, F41, F42

Keywords: International Business Cycles, Synchronization, Financial integration, Trade integration, Globalization.

Author's E-Mail Address: eric.monnet@banque-france.fr; dpuy@,imf.org;

\footnotetext{
${ }^{1}$ We are grateful to Lars E.O Svenson, Romain Duval, Giovanni Dell'Ariccia, Sole Martinez Peria, Deniz Igan and all members of the Macro Financial Division of the IMF Research department for very useful comments and feedback. The opinions expressed herein are solely the responsibility of the authors and should not be interpreted as reflecting those of the IMF, Banque de France, the Eurosystem or anyone else associated with these institutions or their policies.
} 


\section{Table of Contents}

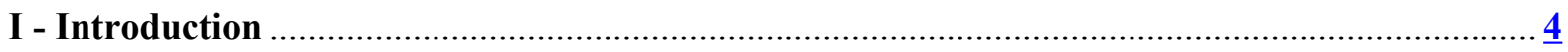

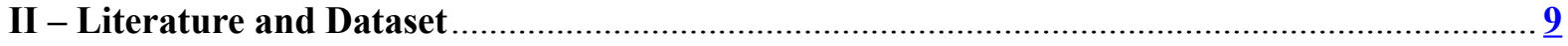

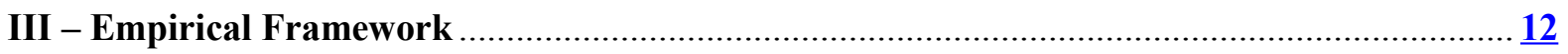

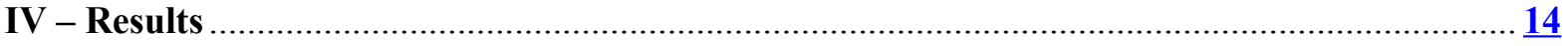

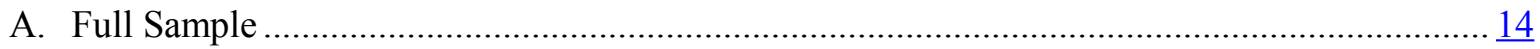

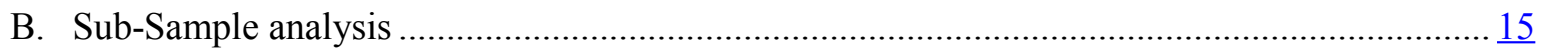

$\mathrm{V}$ - How does financial and trade integration affect co-movement with the world cycle?.......... $\underline{\mathbf{2 0}}$

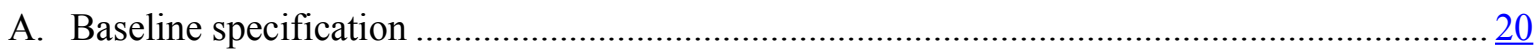

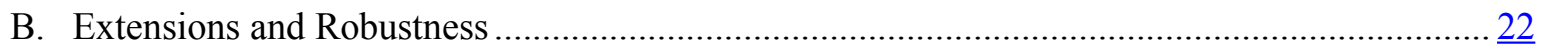

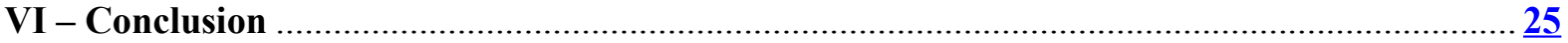

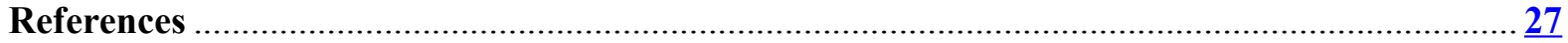

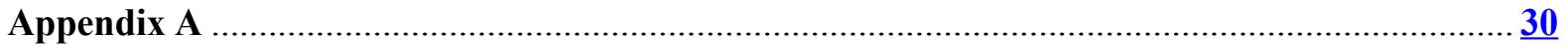

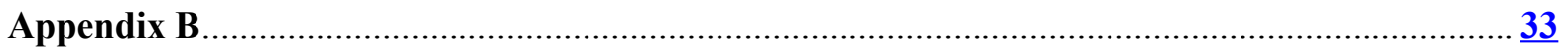

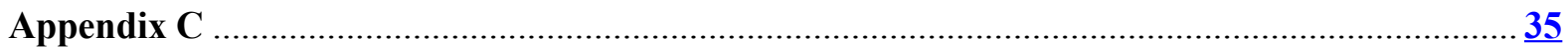




\section{I- Introduction}

The synchronized collapse in output in a number of advanced and emerging markets in the wake of the global financial crisis has reinforced the view that economic and financial globalization generates intense co-movement across countries. Although economic theory is still inconclusive as to the exact effect of integration on the properties of business cycle comovement, a number of empirical and policy contributions have argued that intense integration - i.e. before the World War I and after the mid 1980s - is associated with a strong degree of business cycle synchronization. ${ }^{2}$ Interestingly, an implicit corollary of that view is that the Bretton Woods era (1946-1971) - a period during which both trade and financial integration were substantially below both pre-WWI and current levels (Bordo, Eichengreen, Irwin, 1999) - is presented as the low point of business cycle synchronization.

There are several reasons behind this popular view. First, at least in theory, the Bretton Woods system was explicitly designed to avoid the international transmission of business cycles (Williamson 1985, Bordo 1993). In an effort to avoid the international spread of depression that affected world economies in the 1930s, the negotiators of Bretton Woods strived to set up an institutional machinery that would not only temper the global business cycle - in particular by avoiding currency wars - but also prevent small shocks or short-term imbalances to propagate. ${ }^{3}$ Second, the channels behind business cycle propagation were de facto shut down under the Bretton Woods agreement. In particular, although they were progressively lifted, the extensive use of capital controls and trade barriers imposed extreme restrictions on the potential contagion mechanisms. As a result, the recent empirical contributions which found more co-movement in the recent period only confirmed the common wisdom.

Still, robust empirical evidence on changes in the nature and strength of global co-movement over the postwar period is still missing. Although a number of empirical contributions have argued that macroeconomic fluctuations have become more closely linked since the collapse of Bretton Woods (e.g Kose, Otrok and Whiteman (2008), Lumsdaine and Prasad (2003), Kose, Prasad and Terrones (2003) and Kose et al. (2003b), Bordo and Helbling (2003)), these

\footnotetext{
${ }^{2}$ For a review of the theoretical literature on the relation between (trade and financial) integration and output correlations, see Kose and Yi (2006). Empirical contributions emphasizing the rise in output co-movement include, inter alia, Lumsdaine and Prasad (2003), Kose, Prasad and Terrones (2003), and Kose, Otrok and Whiteman (2003) and Kose, Otrok and Whiteman (2008). These contributions are discussed in more detail below.

${ }^{3}$ The use of IMF credits and international reserves, combined with extensive capital controls, were supposed to insulate economies from each other and allow them to pursue internal objective (price stability or employment). In practice, such a design did not prevent large and persistent imbalances. See Bordo (1993) and Monnet and Puy (2015).
} 
studies share two important data limitations. First, because quarterly GDP statistics computed by the OECD - which have been extensively used in empirical contributions - are not available before 1960, these studies cannot identify a world cycle between 1950 and 1960 . This implies that the sample used for estimation always excludes two important global cycles of the Bretton Woods era (1952-1953 and 1957-1958). Second, even when they are reported, quarterly GDP data in 1960s and 1970s are usually the result of linear interpolations. As we discuss below, we find that this method introduces a bias, which underestimates severely the amount of co-movement across OECD countries between 1960 and 1973. ${ }^{4}$ As a result, the common wisdom builds, at this stage, on empirical studies which consistently underestimated the amount of co-movement during Bretton Woods.

The objective of this paper is to test empirically whether the world co-moves more in the recent "globalization" period than it used to. To do so, we first address the data issue described above. Instead of relying on GDP data, we assemble a new panel of quarterly Industrial Production (IP) indexes covering the whole post-war period. Because IP data are not available in a digital format between 1950 and 1960, we collect missing data directly from International Financial Statistics (IFS) paper volumes at the IMF archives. With this procedure, we are able to assemble a final panel of 21 countries - seventeen advanced and four emerging - between 1950 Q1 and 2014 Q4. After showing that IP indexes are very accurate trackers of real activity in the past (and in the present), we then estimate a dynamic latent factor model as in Kose, Otrok and Whiteman (2003, 2008) and use variance decompositions to measure the strength of co-movement at the world level. Building on the higher frequency and longer coverage of the database, we estimate the factor model on the full sample and on four different sub-periods: (i) the Bretton Woods period (1951 Q1-1971 Q2), the first common shock period (1972 Q1-1983 Q4), the Globalization period (1984 Q12006 Q4) and the second common shock period (2007 Q1-2014 Q4). ${ }^{5}$ Factors and Variance decompositions are then compared across samples.

Our key findings are as follows. First, we estimate a very precise world factor over the full sample, including the Bretton Woods period. To support our statistical analysis, we conduct a narrative analysis based on IMF annual reports published between 1950 and 2014, and find that the world cycles described in IMF reports match almost exactly the turning points and

\footnotetext{
${ }^{4}$ For most OECD countries, quarterly GDP statistics are not based on output data (coming either from retail, manufacturing or survey data) at least until the mid 1980s. We show below that this procedure washes out most of the cyclical dynamics at the country level, making it impossible to detect co-movement by construction.

${ }^{5}$ We also refer loosely to the first common shock period as the "oil shocks period" and to the second common shocks as the Global Financial Crisis (GFC) period. Although the GFC (2007-2014) naturally corresponds to a period of intense globalization, we use this labeling because a key objective of this paper is to compare the intensity of co-movement under low integration (Bretton Woods) to its counterpart under deep integration (1984 to 2006).
} 
phases identified by our estimation procedure. Second, we find that the quantitative impact of the world cycle varies significantly across periods. As expected, the share of variance in output accounted for by the global dynamic increases dramatically during common shocks periods (1972-1983 and 2007-2014) for almost all countries. Contrary to the common wisdom however, we do not find any difference in co-movement between Bretton Woods (1950-1971) and the Globalization period (1984-2006). On average, the global dynamic accounts for $20 \%$ of output volatility in both periods. Third, we find that, although the average co-movement in both periods is unchanged, the way individual countries co-move with the rest of the world has changed substantially over time. Countries such as the UK, Belgium or Sweden, who were strongly co-moving with the rest of the world during Bretton Woods, have been significantly disconnected from the world dynamic during the Globalization period. In contrast, countries such as France, Italy and to a minor extent the US, who were dominated by idiosyncratic dynamics under Bretton Woods, have been resynchronizing with the world cycle. A significant number of countries are also found to display constantly low (or high) degree of synchronization with the rest of the world in both periods.

Why do some countries "de-synchronize" while others "re-synchronize"? In the second part of the paper, we study the role of trade and financial integration in rationalizing these findings. Using a simple panel regression controlling for both country and time fixed effects, we show that the changes in synchronization can be explained, to a great extent, by trade and financial integration patterns. We find that financial integration has, on average, a negative impact on the synchronization with the world cycle, although this average effect conceals an important asymmetry. In normal times, we find that increasing financial integration by $10 \%-$ measured by the ratio of Foreign Assets plus Foreign Liabilities to GDP - decreases comovement with the rest of the world by $1 \%$. However, this "de-synchronizing" effect is compensated by an opposite force in financial crisis periods, during which integrated economies tend to co-move more than others. Although the net effect remains negative, this asymmetry shows that if financial integration de-synchronizes national outputs from the world cycle, the magnitude of this effect depends crucially on the type of shock hitting the world economy. For instance, financial integration did not seem to have an (additional) impact during the oil shocks period.

We also find that if trade integration tends to increase co-movement with the rest of the world, this effect disappears when considering only advanced economies and is not restored by the use of interaction terms (to uncover potential asymmetries) or other proxies of trade integration (e.g. value-added trade rather gross trade). This suggests that trade integration only affects the strength of co-movement with the global at early stages of the process. Finally, we find that the other variables that have been discussed in the literature, such as the degree of economic specialization and the foreign exchange regime, are not significant determinants of the synchronization of a country with the global dynamic. 
Taken together, our findings are well connected to several literatures. First, our findings naturally contribute to the empirical literature on international business cycle, in particular to Lumsdaine and Prasad (2003), Kose, Prasad and Terrones (2003), and Kose, Otrok and Whiteman (2008). Contrary to these contributions however, we do not find any empirical evidence that countries co-moved more during twenty years of intense trade and financial globalization than they did during the twenty years of Bretton Woods. In addition, the use of a quarterly dataset over a long sample allows us to investigate the determinants of changes in co-movement patterns over time. To our knowledge, existing contributions were limited to cross-section analysis, which did not control for important (time and country) fixed effects (in particular Kose, Prasad and Terrones (2003), and Kose, Otrok and Whiteman (2003)).

Second, our results illustrate the role of financial and trade linkages in affecting output comovement across countries. In general, the positive impact of trade is in line with the vast literature documenting the positive impact of trade integration on output correlations. ${ }^{6}$ The strong and asymmetric impact of financial integration we identify echoes the recent empirical findings of Kalemli-Ozcan, Papaioannou and Perri (2013), Kalemli-Ozcan, Papaioannou and Peydro (2013) and Duval et al. (2015). Contrary to most empirical studies that reported a positive link between financial integration and output synchronization, these studies identified (i) a strong negative effect of banking integration on output synchronization once global shocks and country-pair heterogeneity are controlled for and (ii) a positive impact of financial integration on output co-movement during financial crisis. We show that this result affects not only country-pairs co-movement patterns but more generally the way countries co-move with the rest of the world, in particular in the long run. ${ }^{7}$ Using a long sample also shows that the asymmetric effect of financial integration exists only in the presence of global financial shock, but not real shocks.

From a theoretical perspective, our results are in line with Heathcote and Perri (2004) and Obstfeld (1994) who present a model in which financial integration reduces international correlations in GDP. ${ }^{8}$ We are also very closely connected to Kalemli-Ozcan, Papaioannou and Perri (2013) who develop a model in which changes in financial integration affect business cycle synchronization differently depending on the nature of the shocks faced by

\footnotetext{
${ }^{6}$ For a recent review see Duval et al. (2015).

${ }^{7}$ Kalemli-Ozcan, Papaioannou and Perri (2013) and Kalemli-Ozcan, Papaioannou and Peydro (2013) used bilateral banking linkages among 20 industrialized countries from 1978 to 2009.

${ }^{8}$ Although the theoretical mechanism used in Heathcote and Perri (2004) is consistent with our finding, we do not find that the US has been de-synchronizing from the rest of the world between 1986 and 2000; a fact that motivates their theoretical exercise. We actually find the opposite empirical result. This discrepancy is easily explained by the sample and the aggregation method used by the authors when comparing correlations of the US with the rest of the world.
} 
economies (real or financial). In this model, financial integration has significant effects on business cycle synchronization, both during tranquil times (where more integration leads to less co-movement) and during crises periods (where more integration leads to more comovement).

A final contribution of this paper is to provide a detailed narrative analysis of the world economic cycle since 1950, based on the information published in IMF annual reports from 1950 to present. This analysis is reported in appendix at the end of the paper. Besides showing that the world cycle estimated from our dynamic latent factor model is strongly corroborated by contemporary publications and historical evidence, this narrative documents the potential drivers of the world business cycles. In particular we find that although the US (and US monetary policy) has clearly driven the global dynamic in several instances (e.g $1960-1961 ; 1979-1982 ; 1984-1986 ; 1999-2002)$, there is no systematic lead of the US over the global business cycle over the post-war period. A US recession does not necessarily affect the global cycle (as in 1953-1954); and a world recession is possible without a US slowdown (e.g. 1976-1977).

From a policy perspective, a corollary of our results is that a low level of integration does not imply, per se, a low level of co-movement in the economic system. Contrary to conventional wisdom (Williamson 1985), we find that the Bretton Woods period was also affected by common cycles, although capital controls were still the norm and financial systems were highly regulated. Conversely, we find that a high level of international financial integration does not always imply stronger co-movement. Whether the risk-sharing effect integration dominates the contagion effect of financial integration depends crucially on the type of shocks hitting the world economy (real vs. financial).

The rest of the paper is constructed as follows. Section II reviews the empirical literature and the dataset used in the paper. Section III presents estimation results for the full sample. Section IV contrasts full sample results with sub-sample results. Section V illustrates the role of finance and trade in rationalizing the results from Section IV. Section VI concludes. A number of robustness checks are also presented in appendix. In particular, we show that all key results (world cycle identification, variance decompositions and changes in synchronization) are robust to the use of GDP in lieu of IP indexes, when such a comparison is possible. 


\section{II- Literature and Dataset}

Several empirical contributions have measured the importance of global co-movement in output over the post-war period. To date, the empirical support for the presence of a world business cycle is well established. Using a Bayesian factor model on a set of macroeconomic aggregates in a 60-country sample between 1960 and 1990, Kose, Otrok and Whiteman (2003) have shown that a common world factor was an important source of output volatility for most countries over that period. This result has been confirmed by a number of other contributions using different sample and/or methodology, and is also confirmed in the present paper. ${ }^{9}$

The rapid increase in globalization has also generated a literature interested in measuring the impact of trade and financial integration on the properties of global co-movement. However, robust empirical evidence on changes in the nature and strength of global co-movement is far less conclusive. With the exception of Stock and Watson (2005) and Doyle and Faust (2005), most empirical contributions have argued that macroeconomic fluctuations have become more closely linked since the collapse of Bretton Woods (BW). Relying on the same quantitative framework as in Kose, Otrok and Whiteman (2003), Kose, Otrok and Whiteman (2008) found that a common factor explains a larger fraction of output volatility in G7 countries during the Globalization period than in the BW period. Similar results are found in Lumsdaine and Prasad (2003) and Kose, Prasad and Terrones (2003). Using a longer perspective for 16 countries and a different method, Bordo and Helbling (2003) also showed that there was a secular trend towards increased synchronization for much of the twentieth century, and that output correlation was much lower during 1942-1973 than during 19732001. Overall, these studies have supported the (common) view that (i) intense integration generates greater business cycle synchronization and that (ii) until the oil shocks of the 1970s, capital controls and autonomous domestic policies implied little output synchronization (Williamson, 1985).

A common feature of all these studies, however, is that they suffer important data limitations. In the absence of quarterly GDP statistics over the whole post-war period for a large cross section of countries, some studies have relied upon annual GDP data (Kose et al. (2003), Mumtaz, Simonelli and Surico (2011)). Besides washing out small and short-lived cycles however, the use of annual GDP data prevents any time comparison because the amount of data is not sufficient to re-estimate the models on sub-samples. To circumvent this issue, several papers have turned to quarterly GDP data (e.g. Kose, Otrok and Whiteman (2008), Doyle and Faust (2005), Stock and Watson (2005)). But this move was made at a significant cost. First, because quarterly GDP statistics computed by the OECD - which have been

\footnotetext{
${ }^{9}$ Using a longer historical dataset from 1860 to 2007 covering 36 countries, Mumtaz, Simonelli and Surico (2011) also identified a global factor in output growth.
} 
extensively used in empirical contributions - are not available before 1960, these studies cannot identify a world cycle between 1950 and 1960. As a result, the sample used for estimation always excludes two important global cycles of the BW era (1952-1953 and 19571958). Second, even when they are reported, quarterly GDP data in 1960s and 1970s are, for most countries, the result of linear interpolations. As we discuss in Appendix A, this procedure washes out most of the cyclical dynamics at the country level, making it almost impossible to detect business cycle co-movement, in particular between 1960 and 1973. These data constraints imply that, at this stage, the common wisdom builds mostly on empirical studies, which consistently underestimated the amount of co-movement during BW.

To circumvent this data issue, this paper relies on a new dataset of quarterly Industrial Production (IP). Besides being a very accurate tracker of real activity in the present and in the past (see below), IP indexes have been produced and reported at a high frequency for a much longer period than GDP statistics and for a larger cross section of countries. More importantly, as opposed to quarterly GDP data, IP indexes are not based on interpolations and ex-post estimations. This implies that the quarterly profile derived from IP indexes are a much more accurate depiction of changes in real activity for the period 1960-1980 than the official quarterly GDP statistics (see Appendix A for a comparison).

To construct our sample of IP indexes we use the following procedure: from 1960 onwards, quarterly IP data are downloaded from International Financial Statistics for the largest sample of countries possible. Because IP data are not available in a digital format between 1950 and 1960, we then collect the missing data directly from IFS paper volumes collected from the IMF archives. After this procedure we find that only 21 countries (17 advanced and 4 emerging) have complete data over the whole sample period. As a result, the final panel of IP data we assemble and use for estimation covers 21 countries between 1950 Q1 and 2014 Q4. ${ }^{10}$ The composition of the final sample is reported in Appendix A.

How good are IP indexes at tracking real activity, in particular in the past? To illustrate their usefulness, we first compare the growth rates derived from the IP indexes collected from IFS paper volumes and digital records to the official GDP profiles of the United States and France; the only two countries for which official quarterly GDP are published and available from 1950 onwards. We find that the series are highly correlated. Over the whole sample period, we find correlations of 0.85 and 0.89 for France and the US respectively. Figure 1 and 2 below illustrate this finding over the period 1950-1972 (see Appendix A for the full sample). Overall we find that IP indexes are very good tracker of real activity (or GDP) in the past and in the present. In fact, as we shall see in Section 4, we find that all quantitative and

10 Although data were available before, we excluded the 1948-1949 period, which was marked by hyperinflation, and exchange rate crises, ending with more than 30 devaluations in September 1949. 
qualitative results are unchanged in a shorter sample for which we are able to use GDP, rather than IP indexes.

Figure 1: France - IP vs GDP Growth (1950-1972)

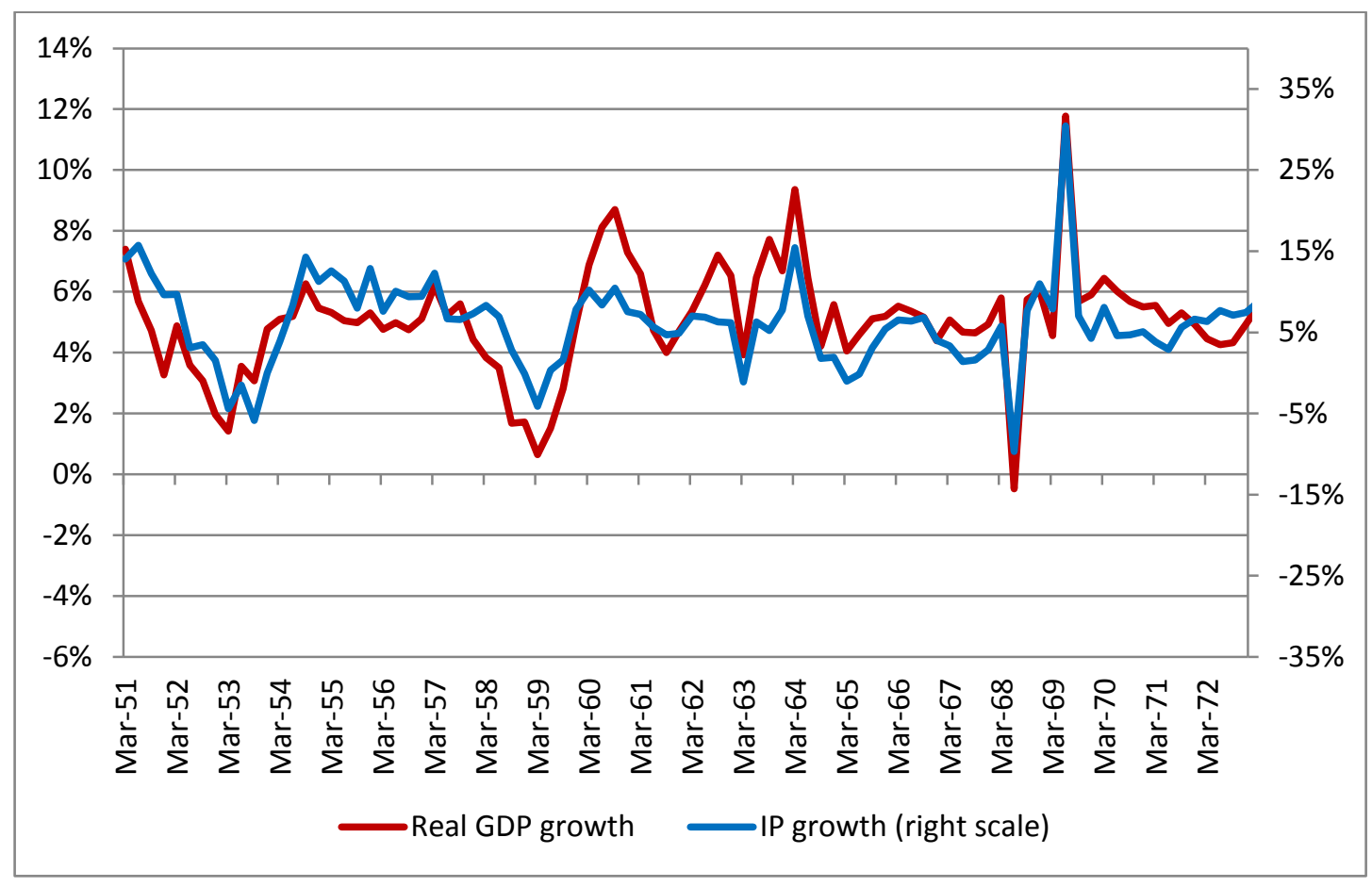

Figure 2: USA - IP vs GDP Growth (1950-1972)

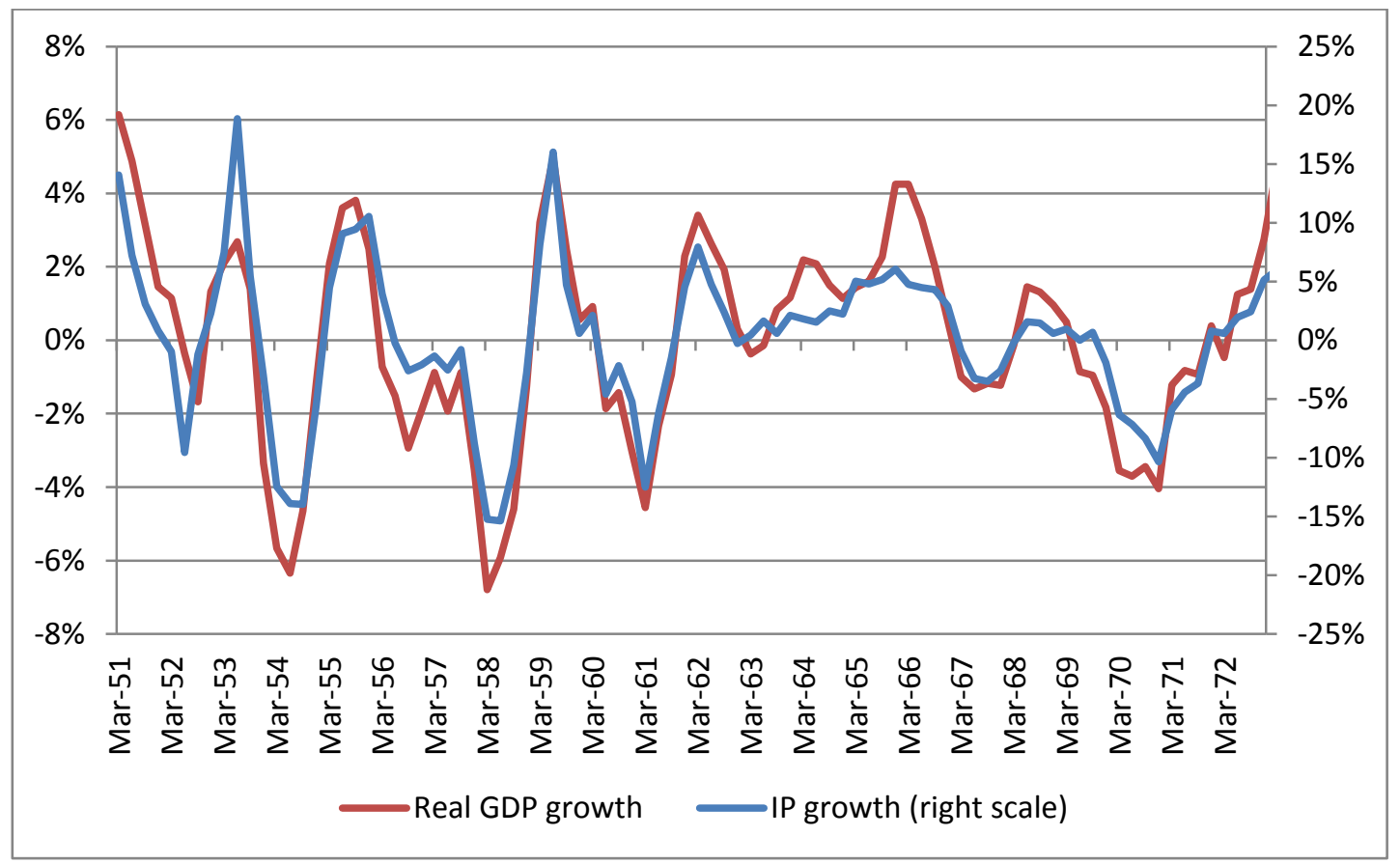




\section{III- Empirical framework}

To enhance the comparability of our results with the previous literature, in particular Kose, Otrok and Whiteman $(2003,2008)$, we rely on the same econometric methodology to assess the importance of a world business cycle. We estimate the following latent factor model:

$y_{i, t}=\beta_{i}^{W} f_{t}^{W}+\beta_{i}^{\text {Region }} f_{t, j}^{\text {Region }}+\varepsilon_{i, t}$

where $y_{i, t}$ is the y-o-y growth rate of IP in country $i$ in quarter $t, f_{t}^{W}$ is the (unobserved) factor affecting all countries in our sample at time $t, f_{t, j}^{\text {Region }}$ is the (unobserved) regional factor affecting all countries belonging to region $j$ at time $t$, and $\beta_{i}^{W}$ and $\beta_{i}^{\text {Region }}$ designate country-specific factor loadings measuring the responses of country $i$ to the common world and regional factors respectively. Finally, $\varepsilon_{i, t}$ is an unobserved country-specific residual factor.

Because we allow factors to follow AR processes, the model in (1) is in fact a dynamic latent factor model. More precisely, we assume that idiosyncratic factors follow an $\operatorname{AR}(p)$ process:

$\varepsilon_{i, t}=\rho_{i, 1} \varepsilon_{i, t-1}+\rho_{i, 2} \varepsilon_{i, t-2}+\cdots+\rho_{i, p} \varepsilon_{i, t-p}+u_{i, t}$

where $u_{i, t} \sim N\left(0, \sigma_{i}^{2}\right)$ and $E\left(u_{i, t}, u_{i, t-s}\right)=0$ for $s \neq 0$ and the world and regional factors follow the respective $\operatorname{AR}(\mathrm{q})$ processes:

$f_{t}^{W}=\rho_{1} f_{t-1}^{W}+\rho_{2} f_{t-2}^{W}+\cdots+\rho_{q} f_{t-q}^{W}+u_{t}^{W}$

$f_{j, t}^{\text {Region }}=\rho_{1, j} f_{t-1}^{\text {Region }}+\rho_{2, j} f_{t-2}^{\text {Region }}+\cdots+\rho_{q, j} f_{t-q}^{\text {Region }}+u_{j, t}^{\text {Region }}$

where $u_{t}^{W} \sim N\left(0, \sigma_{W}^{2}\right), u_{j, t}^{\text {Region }} \sim N\left(0, \sigma_{j}^{2}\right)$ and $E\left(u_{t}^{W}, u_{t-s}^{W}\right)=E\left(u_{j, t}, u_{j, t-s}\right)=0$ for $s \neq 0$.

Given that the factors are unobservable, standard regression methods do not allow for the estimation of the model. As a consequence, we rely on Bayesian techniques as in Kose, Otrok and Whiteman $(2003,2008)$ for estimation. As it is standard in the literature, as a first step, we normalize the sign of the factor/loadings by (i) restricting the loading on the world factor for the first country in our sample to be positive and (ii) restricting the loadings on the regional factor for one country in each region to be positive. Second, to normalize the scales, we assume that each of the factor variances is equal to 1 . Note that these normalizations do not affect the qualitative results and simply allow the identification of the model. In addition, we use Bayesian techniques with data augmentation to estimate the parameters and factors in (1)-(4). This implies simulating draws from complete posterior distribution for the model 
parameters and factors and successively drawing from a series of conditional distributions using a Markov Chain Monte Carlo (MCMC) procedure. Posterior distribution properties for the model parameters and factors are based on 300,000 MCMC replications after 30,000 burn-in replications.

Following Kose, Otrok and Whiteman (2003), we use the following conjugate priors when estimating the model:

$\left(\beta_{i}^{W}, \beta_{i}^{\text {Region }}\right)^{\prime} \sim N\left(0, I_{2}\right)$

$\left(\rho_{i, 1}, \ldots, \rho_{i, p}\right)^{\prime} \sim N\left(0, \operatorname{diag}\left(1,0.5, \ldots, 0.5^{p-1}\right)\right.$

$\left(\rho_{1}, \ldots, \rho_{q}\right)^{\prime} \sim N\left(0, \operatorname{diag}\left(1,0.5, \ldots, 0.5^{q-1}\right)\right.$

$\left(\rho_{1, j}, \ldots, \rho_{q, j}\right)^{\prime} \sim N\left(0, \operatorname{diag}\left(1,0.5, \ldots, 0.5^{q-1}\right)\right.$

$\left(\sigma_{i}^{2}\right)^{\prime} \sim I G(6,0.001)$

Where $\mathrm{i}=1, \ldots, 21$ and IG denotes the Inverse Gamma distribution, implying a rather diffuse prior on the innovations variance. We also assume that the AR processes in (2)-(4) are stationary. In practice, in our implementation, we set the length of both the idiosyncratic and factor auto-regressive polynomials to 2. However, other (non-zero) values for $p$ and $q$ were tried with no substantial differences in the results. Similarly, reasonable deviations in priors did not generate any notable differences in the results presented below.

Besides estimating the factors, we are particularly interested in measuring the influence of the common world factor on the different countries in our sample. To do so, we compute variance decompositions, $\theta_{i}^{W}$, which denote the share of variance in the output of country $i$ which is attributable to the world dynamic and is computed as follows:

$\theta_{i}^{W}=\left(\beta_{i}^{W}\right)^{2} \operatorname{var}\left(f_{t}^{W}\right) / \operatorname{var}\left(y_{i, t}\right)$

Finally, models are estimated using two regions, namely: (i) Continental Europe (ii) Northern Europe (UK and Nordic countries), America and Asia. Note that although alternative regional decompositions could be used, the key results derived below are not sensitive to these decompositions as variance decompositions are invariant to the regional classification. 


\section{IV- Results}

Section A first reports the results of the estimation for the full sample. Results for subsamples are contrasted with the full sample results in section B.

\section{A. World Factor and Variance Decompositions - Full Sample (1950 - 2014)}

Figure 3 displays the mean posterior distribution of the world factor, along with 5 and $95 \%$ quantile bands. Figure 4 reports, for each country, the variance decompositions computed using (10) along with corresponding quantile bands. Several important findings emerge.

First, besides being precisely estimated, the world factor captures the major economic events and cycles of the last 65 years, such as the oil shocks and the Global Financial Crisis (GFC). We postpone a complete discussion of the peaks and troughs identified by the global cycle to Appendix $\mathrm{C}$, which is dedicated to a comparison of the peaks and troughs identified by the factor decomposition with a narrative analysis of the world cycle based on published IMF annual reports from 1950 to 2014. At this stage we only emphasize that world cycles described in IMF annual reports match almost exactly the turning points identified by our procedure.

Second, the variance decompositions point to a significant influence of a world business cycle over the postwar period. With only a few exceptions, the share of volatility in IP accounted for by the world dynamic is above one third in almost all advanced economies, with France, Germany, Italy, Belgium, Austria and Japan crossing the 50\% threshold. In contrast, Ireland, Denmark, Norway, and emerging markets do not seem to be highly affected by the world cycle. On average we find that the world dynamic accounted for $37 \%$ of the volatility in Industrial Production of the 21 countries in our sample.

Several robustness checks are performed in Appendix B. First, we find that using quarterly GDP statistics (when available) does not change the shape or the strength of the world factor. Re-estimating the model on quarterly GDP statistics from 1973 onwards and comparing the results to those obtained using IP data, we find that the world factors and the variance decompositions are almost identical. In fact, our variance decompositions are also close to those estimated in Kose, Otrok and Whiteman (2003), which are computed using annual GDP data between 1960-1990 only, but for 60 countries. However, as the next section shows, such results conceal very important differences over time, even within countries. 
Figure 3: IP World Factor - Full Sample (1950 Q1-2014 Q4)

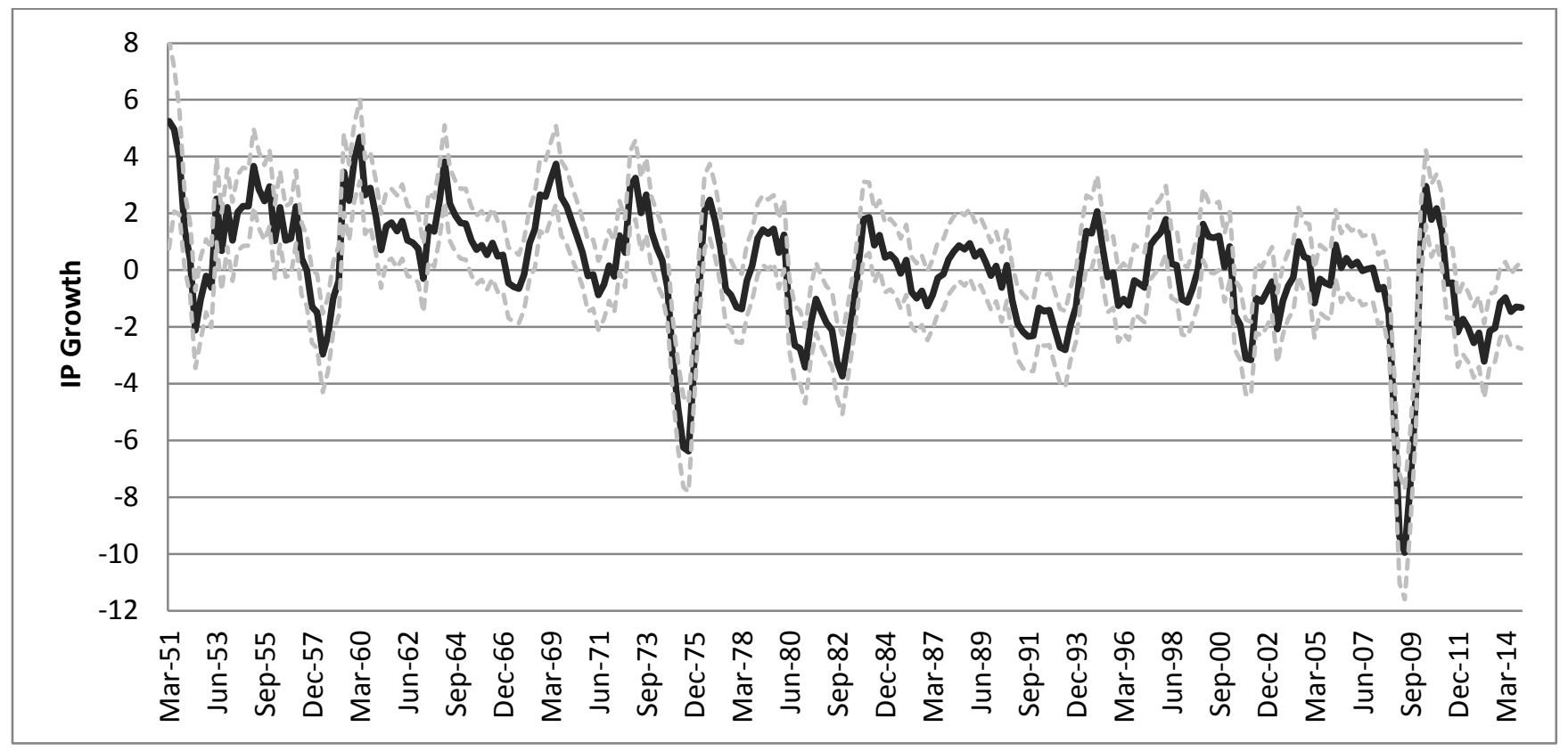

Figure 4: Variance Decompositions - Full Sample (1950 Q1-2014 Q4)

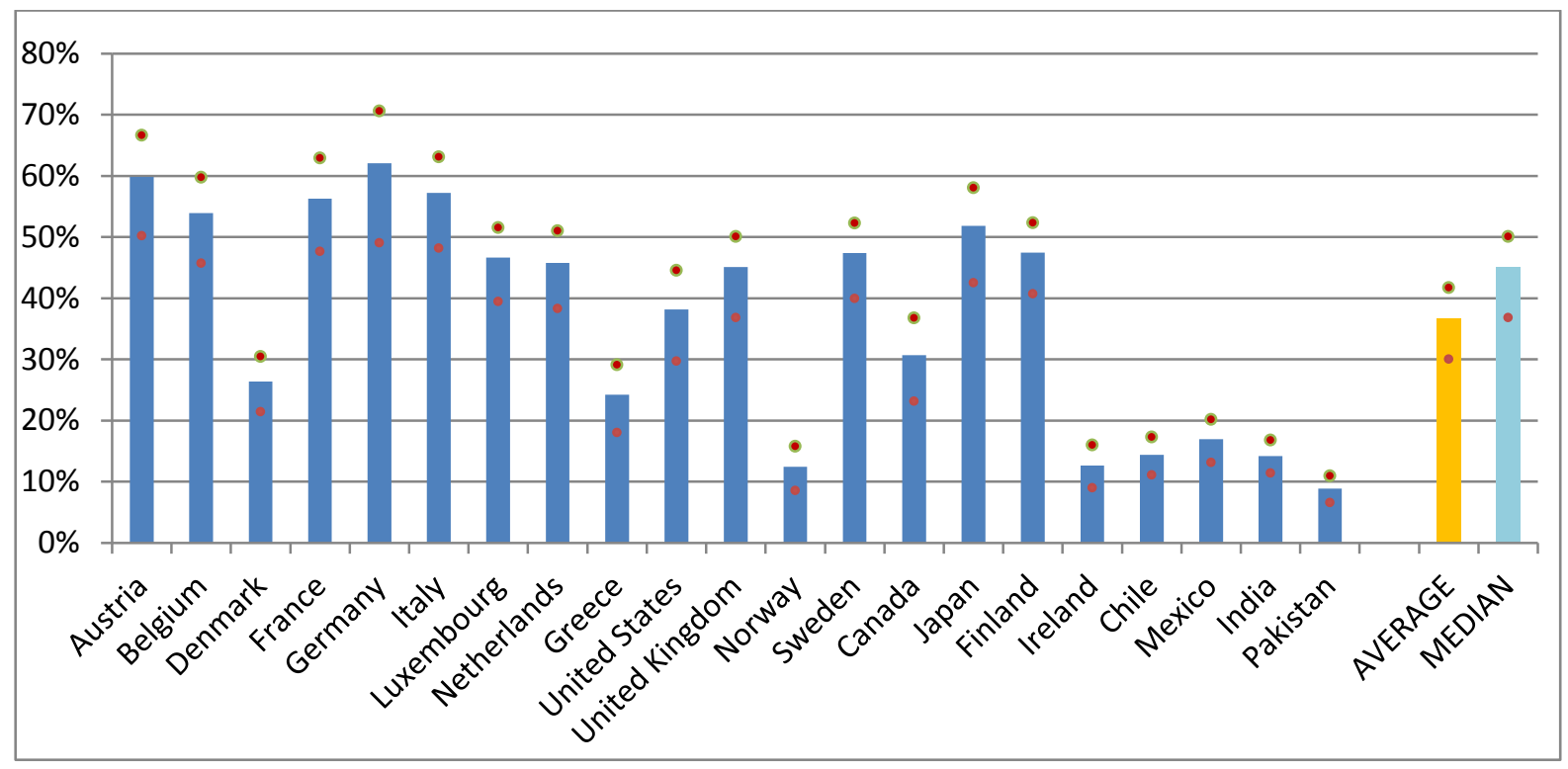

Note: Dots report the 5 and 95 percentiles of the posterior distribution.

B. World Factor and Variance Decompositions - Sub Sample Analysis

Has the strength of the world business cycle really changed over the last 65 years? To address this question, we re-estimate the factor model using four sub-periods: (i) the Bretton Woods period (1951 Q1-1971 Q4), the first common shock period (1972 Q1-1983 Q4), the 
Globalization period (1984 Q1-2006 Q4) and the second common shock period (2007 Q12014 Q4). We also refer to the first common shock period as the "oil shocks" period and the second common shock period as the Global Financial Crisis (GFC).

In line with Kose, Otrok and Whiteman (2008), we isolate periods of well-known global (or common) shocks because they inflate mechanically the amount of co-movement at the world level. The decade ranging from 1973 to 1983, in particular, features the demise of the BW system, two oils shocks and the widespread use of contractionary monetary policy in almost all advanced economies starting 1979. Similarly, the period from 2007 to 2014 was characterized by the GFC and the European debt crisis. Among other things, this procedure allows us to explore the ultimate object of interest of this paper, namely the strength of global co-movement under "normal" macroeconomic fluctuations. In that respect, both periods stand out as relatively tranquil periods of economic fluctuations. The Bretton Woods sample (1950-1971) is notable for its steady growth and stable business cycles dynamics, whereas the Globalization period (1984-2006) captures most of the Great Moderation. In addition, both periods are almost of equal length ( 21 vs. 22 years). On the other hand, these two periods also display very strong structural differences that should, at least intuitively, affect the nature of the world business cycle. In particular, the Bretton Woods period is marked by historically low financial and trade integration, a generalized fixed exchange rate regime and pro-cyclical monetary and fiscal policies, whereas the Globalization period is marked by a strong acceleration of financial and commercial integration and a wider use of flexible exchange rates and inflation targeting (Bordo 1993, Bordo et al. 1999).

Figure 5 plots the estimated world factor for the two sub-periods, along with the world factor for the full sample estimated in the previous section. Shaded areas refer to the periods of common shocks. Figures 6-8 report the variance decompositions for the respective subperiods and contrast them with the results from the full sample. The key findings are as follows. 
Figure 5: IP World Factor - Sub-Samples

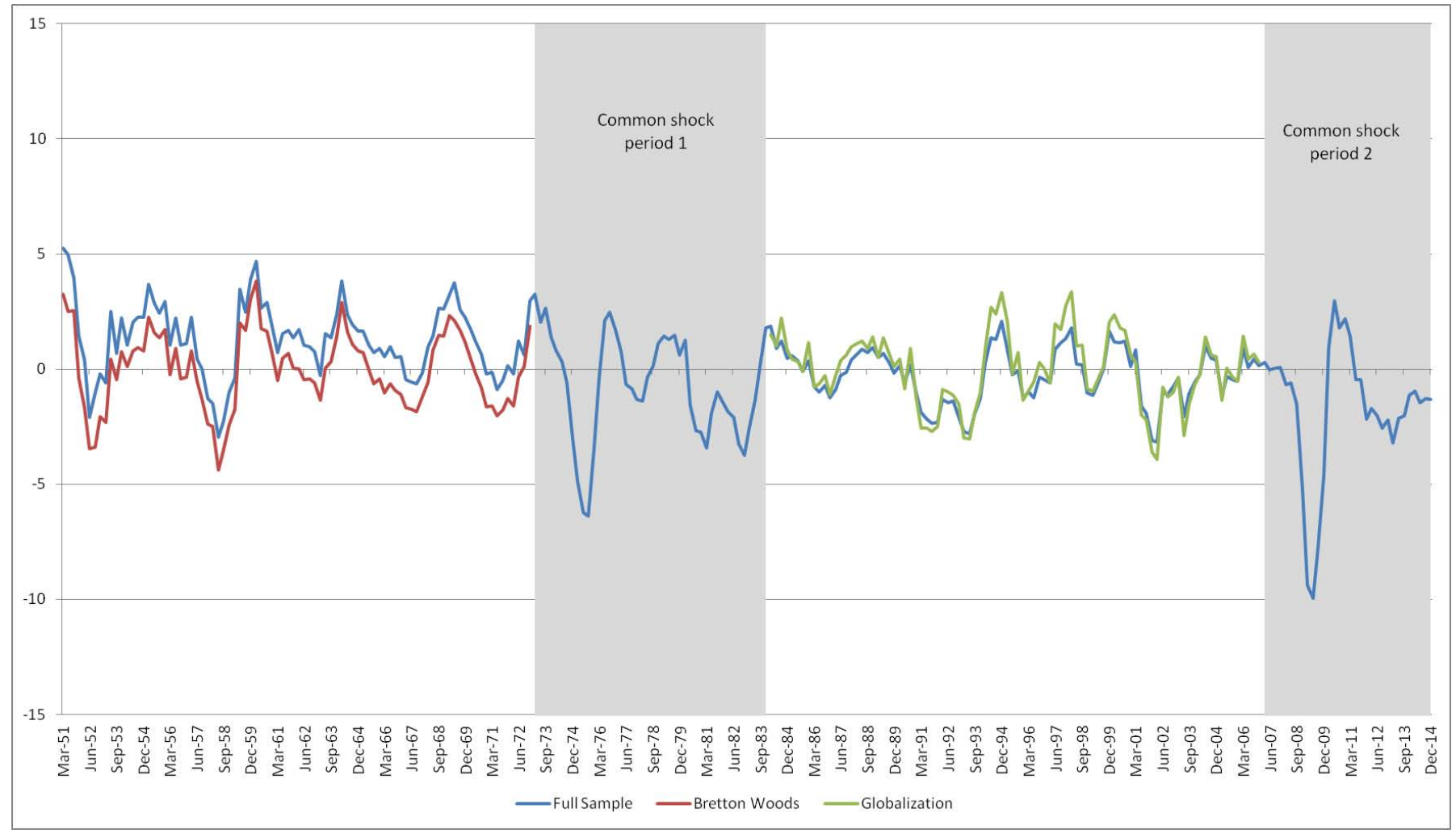

Figure 6: Variance Decompositions by Country and Sub-Sample

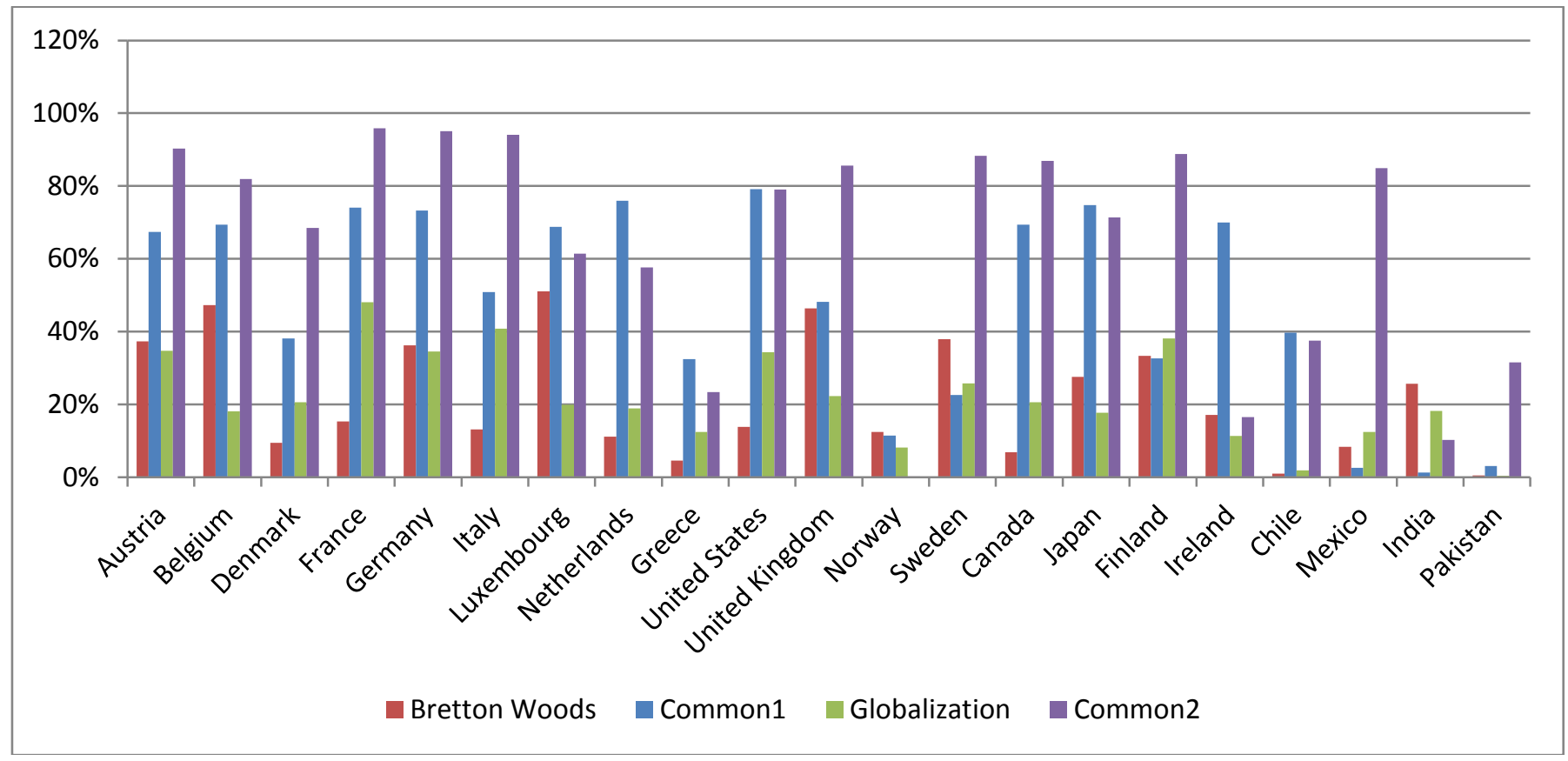


First, as expected, we find that the estimates of the world factors are unchanged when we split the samples (Figure 5). Second, we find that the share of variance explained by the world dynamic varies significantly across sub-samples and countries. Over time, countries also experience significant changes in the way they co-move with the rest of the world.

In general, we find that the full sample result is significantly inflated by the two periods of common shocks (Figure 6 and 7). After averaging the variance decompositions across countries for each sub-sample, we find that the global dynamic was accounting for more than half of the variance of individual countries' output during the first common shock period, and more than $65 \%$ during the second. More importantly, we find that once periods of global turmoil are excluded, the quantitative importance of the common factor is essentially the same between the Bretton Woods period and the Globalization period (Figure 7). Among other things, this result shows that when we use a longer sample with more countries, we do not find empirical support for the view that the recent period (starting in the mid-1980s), at least before the 2007 crisis, was associated with more co-movement at the global level (e.g Kose, Otrok and Whiteman (2008)). Interestingly, we find that this result is also corroborated by the narrative analysis of world economic cycles in Appendix C. Although average growth was higher during the 1950s and 1960s, our narrative analysis shows that Bretton Woods was marked by substantial business cycle fluctuations. As reminded by Swoboda (1983), the main motivation for a shift toward (partially) floating exchange rates in 1971 was to desynchronize individual countries from the rest of the world and to avoid the balance of payment constraints implied by the peg (despite capital controls). ${ }^{11}$

Another important finding is that although the average co-movement we observe is unchanged, the way countries co-move with the rest of the world has changed substantially between Bretton Woods and the Globalization period (Figure 8). Countries such as Austria, Germany, Finland and Sweden are found to co-move substantially with the rest of the world in both periods whereas a significant number of countries, such as Netherlands, Norway, Ireland, as well as most emerging markets, display a relatively low co-movement with the rest of the world in both periods. On the other hand, important changes between the two periods can be observed. The UK, Belgium, and Luxembourg have been significantly disconnected from the world dynamic during the Globalization period, whereas France, Italy and to a minor extent the US have been re-synchronizing with the world cycle. These dynamics (de-synchronization, re-synchronization) can be easily seen graphically and are found to be robust, once again, to the use of GDP in lieu of IP growth rates. ${ }^{12}$ Next section turns to a rationalization of this finding.

\footnotetext{
${ }^{11}$ The important role of monetary policy and balance of payments constraints for the business cycles of several countries during this period has been discussed by Romer \& Romer (2002) and Monnet (2014).

${ }^{12}$ Results available on request.
} 
Figure 7 - Variance Decompositions Average - Full Sample vs. Sub sample

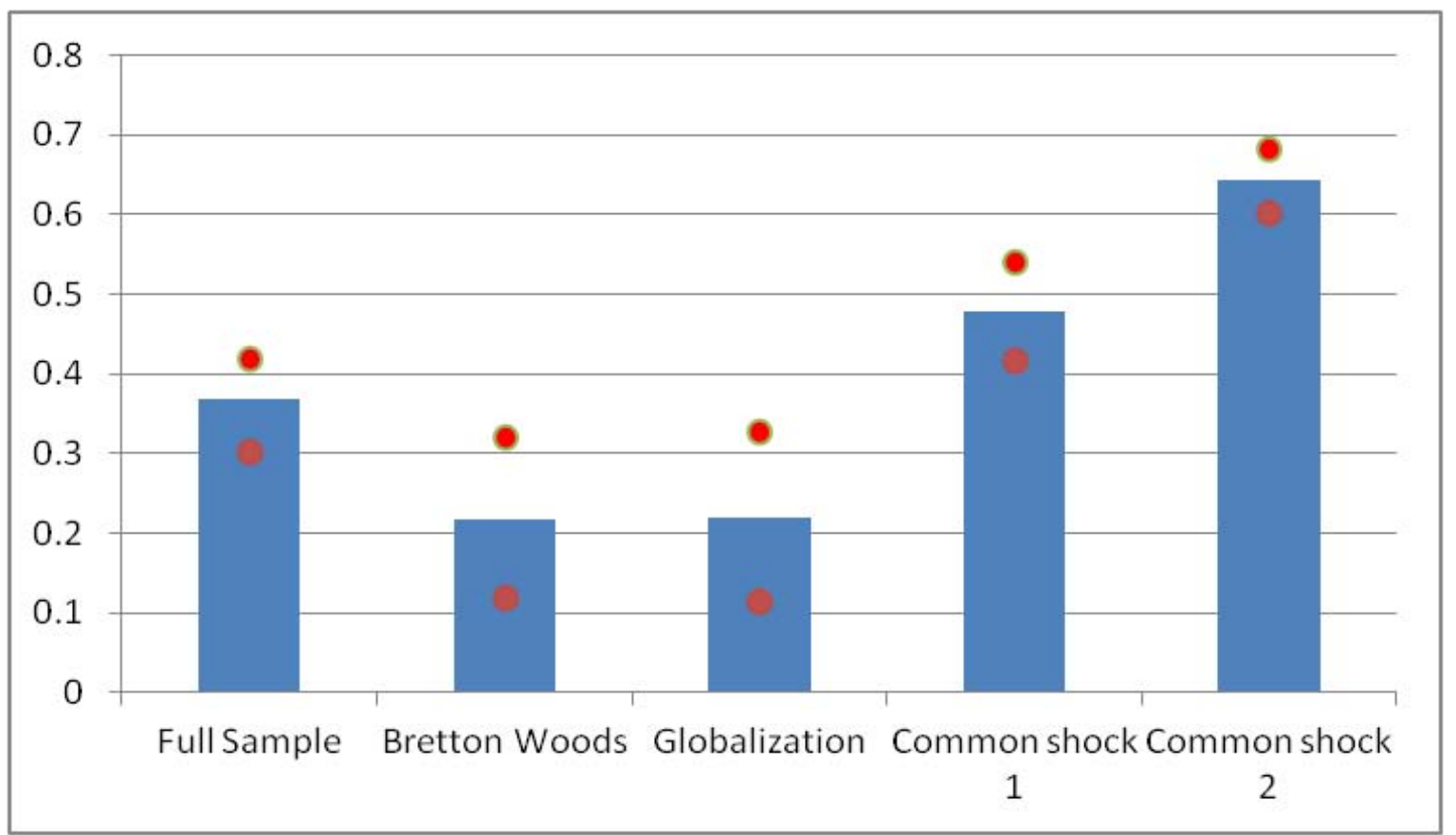

Note: averages are computed across all 21 countries for each sub-sample. Dots report the 5 and 95 percentiles of the posterior distribution.

Figure 8 - Variance Decompositions - Bretton Woods vs. Globalization

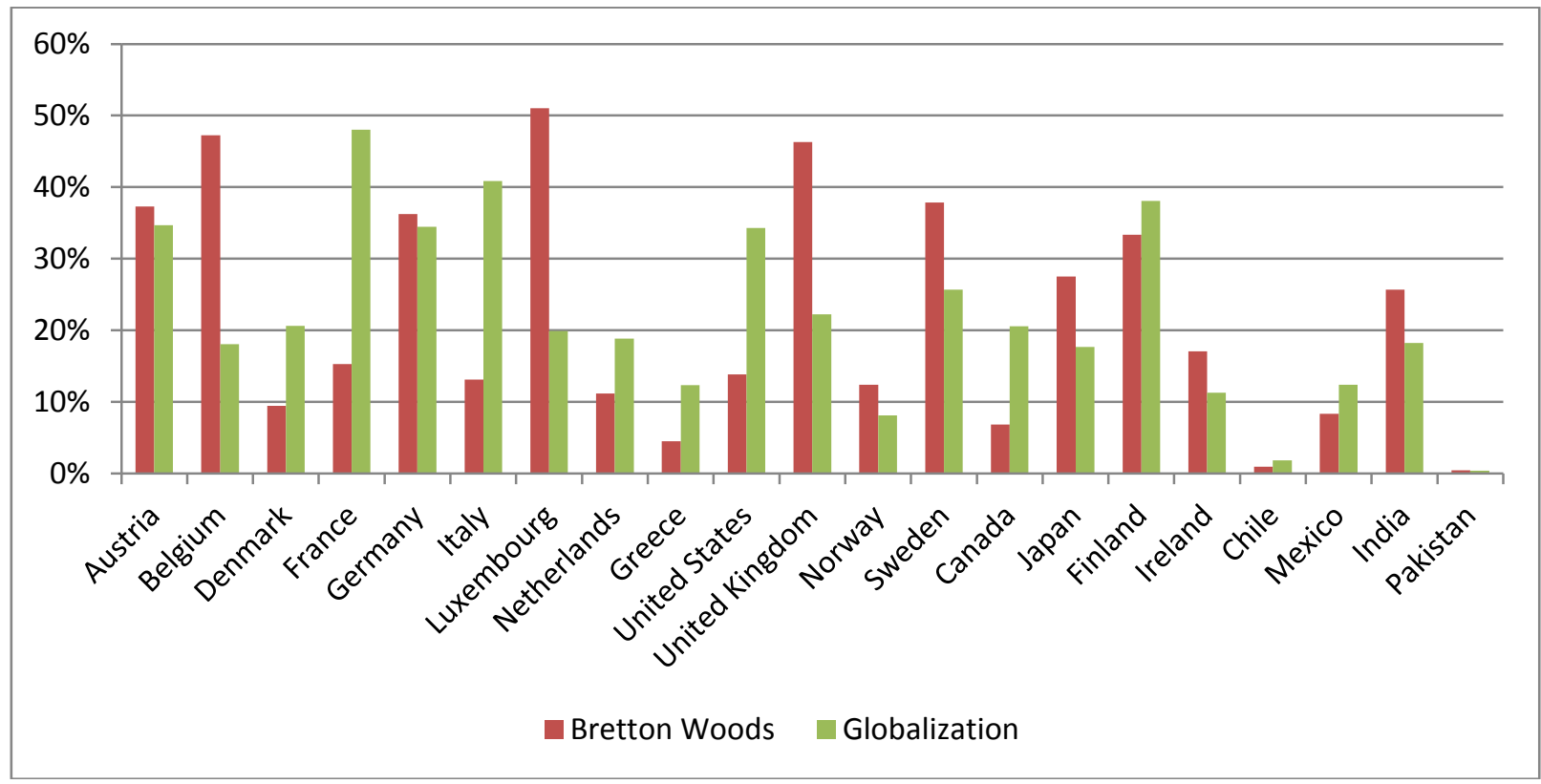




\section{V- How does financial and trade integration affect co-movement with the rest of the world?}

\section{A. Baseline specification}

Can trade and financial integration patterns explain why some countries change the way they co-move with the rest of the world? To answer this question, we run the following panel regression:

$$
\begin{gathered}
\theta_{i, t}^{W}=\beta_{1} . \text { Trade_Int }_{i, t}+\beta_{2} . \text { Financial_Int }_{i, t}+\beta_{3} . \text { Manuf }_{i, t}+\alpha_{i}+d_{t}+\varepsilon_{i, t} \\
t=1,2,3,4 \\
i=1, \ldots, 20
\end{gathered}
$$

Where $\theta_{i, t}^{W}$ designates the share of variance accounted for by the global factor for country $i$ in period $t$ (plotted in Figure 6); Trade_Int $t_{i, t}$ captures the level of trade integration of country $i$ in period $t$; Financial_Int $t_{i, t}$ captures the level of financial integration of country $i$ in period $t$; Manuf $_{i, t}$ measures the share of Manufacturing as a percentage of GDP; $\alpha_{i}$ captures country-fixed effects and $d_{t}$ are time dummies capturing time fixed effects. Period 1 designates the Bretton Woods period; period 2 the first common shock period (or oil shocks); period 3 the Globalization period; and period 4, the GFC period. In practice, we measure trade integration by computing the average ratio of Exports plus Imports to GDP over each sub-sample for each country. ${ }^{13}$ Similarly, we measure financial integration using the average ratio of Foreign Assets plus Foreign Liabilities to GDP over each sub-sample for each country. We also include the share of manufacturing (as \% of GDP). Although we show that this variable is not significant, it serves as a control, as one might expect countries with strong manufacturing sector to co-move more with the rest of the world by construction. Summary statistics and sources about variables used in the estimation are reported in Appendix A.

As expected, the inclusion of both time and country fixed effects helps us controlling for the presence of (i) obvious common shocks scaling up all countries at the same time, in particular in period 2 and 4 and (ii) country fixed effects, since some countries always comove less (or more) than others (e.g Norway or Germany). Although this implies that we cannot say much about the between-variation in the panel, the within-variation is clearly the object of interest in our paper. More importantly, the inclusion of fixed effects allows us to assess, in a rigorous way, the importance of trade and financial integration in affecting comovement patterns. To date, important contributions have limited their analysis to cross-

\footnotetext{
${ }^{13}$ Note that in the baseline we use, for each country, the sum of exports and imports to the other countries in the sample. Not to all countries of the world. However, using all flows yields the same results.
} 
section analysis, or to panel estimators without the inclusion of fixed effects, implying potentially a significant bias in the results (see in particular Kose, Prasad and Terrones (2003)).

Table 1 reports the result of the panel regressions, distinguishing between results for the full sample or for advanced countries only. Standard errors are clustered by country in all estimations. Columns 1 and 2 present results for the baseline regression in (11). Columns 3 to 6 present results when financial integration and trade integration measures are interacted with time dummies to investigate the presence of potential asymmetries during periods of common shocks. As we shall see, this allows us to isolate the effect of financial integration in normal times from its effect in crisis times.

Although the number of observation used for estimation is small, the panel regression yields striking results, some of which are well connected to recent empirical contributions. First, we find that trade integration tends to increase co-movement with the rest of the world. However, this effect depends crucially on the presence of emerging markets in our sample. This suggests that increasing trade integration has a non-linear effect, affecting strongly the strength of co-movement at a lower stage, but less so when countries have already reached a high degree of trade openness. Second, we find that financial integration has, on average, a negative impact on the synchronization with the business cycle (Columns (1) and (2)), and that this effect is true even when emerging markets are dropped. However this average effect conceals an asymmetric effect: when using the interaction term, the negative impact of financial integration more than triples and the precision of the estimate improves (Columns (5) and (6)). Quantitatively, we find that increasing financial integration by $10 \%$ decreases co-movement with the rest of the world by $1 \%$. As a result, a $200 \%$ increase - the average change over the sample of advanced countries - is associated with a decrease in co-movement of 20 to $25 \%$, depending on the sample considered. On the other hand, a strong positive impact appears in financial crisis periods. In that case, a $200 \%$ increase in financial integration would imply an increase in co-movement of $14 \%$ with the rest of the world. However, the total net effect remains negative. This result is also robust to the exclusion of emerging markets from the sample. Third and finally, we do not find evidence of other asymmetries. In particular, financial integration does seem to matter when real (rather than financial) shocks hit the world economy. Similarly, trade integration does not have a separate effect during periods of global shocks (either real or financial).

In normal times, the negative impact of financial integration can be seen graphically in Figure 9, which plots the change in financial integration against the change in co-movement with the world business cycle between Bretton Woods and the Globalization period for advanced economies. This figure shows clearly that countries which have accelerated their financial integration (UK, Belgium, Sweden) have de-synchronized themselves from the 
global dynamic, whereas countries with a slower pace of financial integration have been moving in the opposite direction (France, Italy and the US).

These results are well connected to other empirical contributions, in particular KalemliOzcan, Papaioannou and Perri (2013), Kalemli-Ozcan, Papaioannou and Peydro (2013). ${ }^{14}$ Contrary to most empirical studies that reported a positive link between financial integration and country-pairs output synchronization, these studies identified (i) a strong negative effect of banking integration on output synchronization once global shocks and country-pair heterogeneity are controlled for and (ii) a positive impact of financial integration on output co-movement during financial crisis. Our results bring further support to these results by in that we find a strong and asymmetric impact of financial integration on co-movement in the long run. Using a long sample also shows that the asymmetric effect of financial integration exists only in the presence of global financial shock, but not global real shocks. Overall, this suggests that financial integration (i) disconnects countries from the global dynamic in tranquil times (ii) reconnects them during global financial shocks and (iii) does not play any (marginal) role during global real shocks.

\section{B. Extensions and Robustness}

This section performs a number of extensions and robustness checks. We report and discuss each of them below, connecting the results to the existing literature. Results are reported in Appendix B. Overall, we find that the significance and magnitude of the key results are almost unchanged to the addition of other controls.

\section{(i) Trade integration measurement}

A possible explanation for the insignificance of the trade integration variable in the full sample is that gross trade openness, measured by the ratio of gross exports plus imports to GDP, is a poor proxy of actual trade integration. Ultimately, valued-added trade, rather than gross exports, matter for growth, and therefore for growth co-movement (Duval et al, 2015). We find, however, that using value-added trade data does not change any of the results. ${ }^{15}$ In particular, the significance of trade integration relies on the presence of EMs in the sample. This is not surprising since working with value-added trade data change levels of trade integration for each country, but does very little to the changes in trade integration at the country level over time. Since we are mainly interested in explaining the within-variation in

\footnotetext{
${ }^{14}$ This asymmetric effect of financial integration is also confirmed in Duval et al.(2015).

${ }^{15}$ Following Duval et al (2015), we use OECD-WTO data on trade in value added to estimate trade integration. Using interaction terms with the value-added trade variable does not improve the significance of the results either.
} 
the panel, switching to value-added trade data has, therefore, very little influence on the key results.

(ii) $\quad$ Specialization

A number of empirical contributions have suggested that specialization might also affect the pattern of co-movement; both through direct and indirect effects. ${ }^{16}$ In particular, both trade and financial openness might, at least in theory, induce greater specialization, which in turn might affect co-movement, although in a non trivial way (see Imbs, 2004 for a thorough discussion). To control for the potential impact of specialization we construct, for each country, a standard Herfindahl index of concentration defined as follows: $H_{i, t}=\sum_{1}^{10} s_{i, t}$, where $s_{i, t}$ designates the share of sector $i$ (out of 10 sectors) in the GDP of a given country at time $t .{ }^{17}$ These indexes are then normalized to range between 0 and 1. Data from both Groningen Growth and Development Center (GGDC) and EU-KLEMS are used to compute the index. We find that including the specialization variable does not affect any of the results, as (i) trade integration remains insignificant and (ii) the magnitude and significance of the coefficients attached to the financial integration variables (level and interaction) are unchanged.

\section{(iii) Exchange rate regime}

Finally, we control for the exchange rate regime using the (updated) exchange rate classification compiled by Ilzetzki, Reinhart and Rogoff (2014). In practice, for each country in our sample, we average the fine classification (ranging from 1 to 14) over each sub-period. By construction, a higher value of the index indicates greater exchange rate flexibility over that particular period of time. Because Euro area countries are classified as fixed (a value of 1) in the original database, we also perform estimations when recoding Euro countries as freely floating (a value of 13). In both cases, we find that the exchange rate regime has not been a major determinant of the synchronization of a country with world output, or that, if exchange rate regimes did matter, their effects are captured by the fixed effects included in the estimations.

\footnotetext{
${ }^{16}$ We refer here to specialization as the concentration of production in a single (or a couple) of sectors. In the context of the literature investigating country-pairs output correlation however, specialization refers more to production similarity between two economies.

${ }^{17}$ The 10 sectors include Agriculture, Mining, Manufacturing, Construction, Utilities, Trade Services, Transport Services, Business Services, Government Services and Personal Services.
} 


\section{Table 1 - Panel Regression Results}

This table presents the results of the baseline panel estimations with fixed effects. In all specifications the dependent variable is the share of variance accounted for by the global factor for country $i$ in period $t$ (plotted in Figure 6). Columns (1) and (2) present results for the baseline regression in (11). Columns (3) to (6) present results when financial integration and trade integration measures are interacted with time dummies to investigate the presence of potential asymmetries during common shocks. Because of the scale of Luxembourg's financial integration ( $25000 \%$ of GDP at the end of our sample), we leave the country out of estimations, so that the number of observations is 80 (and not 84 ).

\begin{tabular}{|c|c|c|c|c|c|c|}
\hline & \begin{tabular}{|c|} 
Full Sample \\
(1) \\
\end{tabular} & $\begin{array}{c}\text { Advanced } \\
\text { (2) } \\
\end{array}$ & $\begin{array}{c}\text { Full Sample } \\
(3)\end{array}$ & $\begin{array}{c}\text { Advanced } \\
\text { (4) } \\
\end{array}$ & $\begin{array}{c}\text { Full Sample } \\
\text { (5) } \\
\end{array}$ & $\begin{array}{c}\text { Advanced } \\
\text { (6) }\end{array}$ \\
\hline Trade_Integration & $\begin{array}{c}1.219 \\
(0.983)\end{array}$ & $\begin{array}{l}-0.185 \\
(0.852)\end{array}$ & $\begin{array}{c}1.039 \\
(1.014)\end{array}$ & $\begin{array}{l}-0.211 \\
(1.043)\end{array}$ & $\begin{array}{l}1.798^{*} \\
(1.009)\end{array}$ & $\begin{array}{c}0.401 \\
(0.885)\end{array}$ \\
\hline Financial_Integration & $\begin{array}{c}-0.0342^{* *} \\
(0.0124)\end{array}$ & $\begin{array}{l}-0.0220^{* *} \\
(0.00975)\end{array}$ & $\begin{array}{c}-0.0341^{* *} \\
(0.0132)\end{array}$ & $\begin{array}{l}-0.0223^{*} \\
(0.0117)\end{array}$ & $\begin{array}{c}-0.113^{* * *} \\
(0.0356)\end{array}$ & $\begin{array}{c}-0.0953^{* *} \\
(0.0324)\end{array}$ \\
\hline Manufacturing & $\begin{array}{l}-1.221 \\
(1.023)\end{array}$ & $\begin{array}{c}0.477 \\
(0.705)\end{array}$ & $\begin{array}{l}-1.056 \\
(0.953)\end{array}$ & $\begin{array}{c}0.514 \\
(0.828)\end{array}$ & $\begin{array}{l}-1.201 \\
(1.077)\end{array}$ & $\begin{array}{c}0.725 \\
(0.802)\end{array}$ \\
\hline Time dummies & & & & & & \\
\hline Oil shocks period (1973-1983) & $\begin{array}{l}18.70^{*} \\
(9.718)\end{array}$ & $\begin{array}{c}35.50^{* * * *} \\
(8.826)\end{array}$ & $\begin{array}{c}9.994 \\
(14.34)\end{array}$ & $\begin{array}{c}33.83^{* *} \\
(15.56)\end{array}$ & $\begin{array}{c}12.93 \\
(15.43)\end{array}$ & $\begin{array}{c}35.51^{* *} \\
(15.78)\end{array}$ \\
\hline Globalization (1984-2006) & $\begin{array}{l}-8.595 \\
(10.15)\end{array}$ & $\begin{array}{c}11.26 \\
(11.16)\end{array}$ & $\begin{array}{l}-6.300 \\
(10.71)\end{array}$ & $\begin{array}{c}11.77 \\
(14.91)\end{array}$ & $\begin{array}{l}-0.345 \\
(10.39)\end{array}$ & $\begin{array}{l}22.02^{*} \\
(10.42)\end{array}$ \\
\hline GFC (2007-2014) & $\begin{array}{l}37.66 * * \\
(17.31)\end{array}$ & $\begin{array}{c}67.66^{* * *} \\
(16.79)\end{array}$ & $\begin{array}{l}35.26^{*} \\
(18.19)\end{array}$ & $\begin{array}{c}67.23^{* * *} \\
(16.45)\end{array}$ & $\begin{array}{c}31.53 \\
(18.89)\end{array}$ & $\begin{array}{c}65.62 * * * \\
(15.82)\end{array}$ \\
\hline Interaction terms & & & & & & \\
\hline Trade_integration*Oil shocks & & & $\begin{array}{c}0.553 \\
(0.468)\end{array}$ & $\begin{array}{l}0.0940 \\
(0.547)\end{array}$ & & \\
\hline Trade_integration*GFC & & & $\begin{array}{c}0.222 \\
(0.456)\end{array}$ & $\begin{array}{l}0.0445 \\
(0.500)\end{array}$ & & \\
\hline Financial_Integration*Oil shocks & & & & & $\begin{array}{l}0.0619 \\
(0.146)\end{array}$ & $\begin{array}{c}-0.00116 \\
(0.140)\end{array}$ \\
\hline Financial_Integration*GFC & & & & & $\begin{array}{c}0.0688^{* *} \\
(0.0285)\end{array}$ & $\begin{array}{l}0.0616^{* *} \\
(0.0272)\end{array}$ \\
\hline constant & $\begin{array}{c}35.39 \\
(21.52)\end{array}$ & $\begin{array}{c}14.77 \\
(13.43)\end{array}$ & $\begin{array}{c}33.86 \\
(21.40)\end{array}$ & $\begin{array}{c}14.23 \\
(11.79)\end{array}$ & $\begin{array}{c}31.71 \\
(22.93)\end{array}$ & $\begin{array}{c}3.749 \\
(23.30)\end{array}$ \\
\hline$N$ & 80 & 64 & 80 & 64 & 80 & 64 \\
\hline R-sq & 0.648 & 0.718 & 0.660 & 0.718 & 0.689 & 0.742 \\
\hline
\end{tabular}

Standard errors in parentheses $* p<0.10 * * p<0.05 * * * p<0.01$ 


\section{Figure 9-Change in Financial Integration vs. Change in Co-movement}

This figure plots the change in financial integration against the change in co-movement with the world business cycle between Bretton Woods and the Globalization period, for the sample of advanced economies. The negative slope illustrates the negative impact of financial integration on co-movement in "normal" times. Note that Ireland, which stands out given the size of its financial integration, is not driving any the key results. In fact, dropping Ireland increases the precision and significance of the coefficients of interest (financial integration and its interaction) without altering any of the other results.

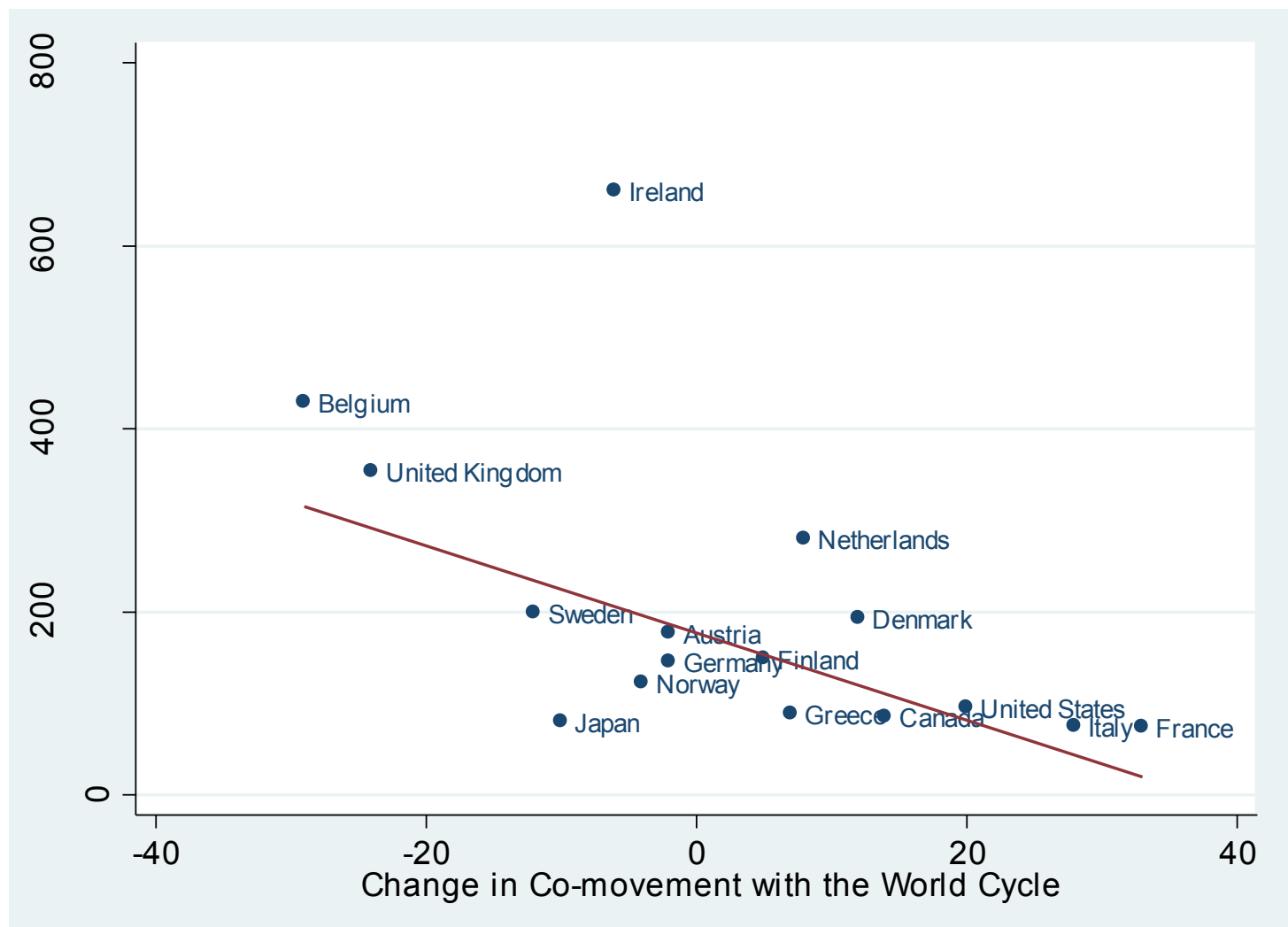

\section{VI- Conclusion}

The global financial and economic crisis reignited the debate on the importance of globalization in shaping output co-movement which has accompanied the long rise of financial and trade integration since the early 1980s (Swodoba 1983, Rodrik 1997, Kose, Prasad, Rogoff Wei, 2006). This paper contributes to this debate by measuring the strength of global co-movement in a new quarterly sample of 21 countries since 1950. Among other things we find that using a longer time series and extending the sample changes considerably the empirically results, as well as the policy messages. After isolating four periods (1950 $1971 ; 1972$ - 1983; 1984 - 2006; 2007 - 2014), we find that the Bretton Woods era was not a period of low co-movement compared to the period between 1984 and 2006, which saw a massive rise in both trade and financial of globalization. At the country level however, we find a robust negative link between financial openness and the correlation with the world 
business cycle, although this effect was dampened after 2007. Inter alia, our results suggest that a low level of integration does not imply a low level of co-movement in the economic system. Contrary to what Rodrik (2002) and others have suggested, we find no evidence that reduced financial and trade integration disconnected countries from foreign shocks or left more room to national economic management in the 1950s and 1960s than during the period of 1984-2006. Our results suggest that reducing financial integration would only decrease comovement in the face of global financial shocks, but would probably increase co-movement in normal times, when the world is dominated by idiosyncratic shocks. 


\section{References}

Bordo, Michael D. 1993, "The Bretton Woods international monetary system: a historical overview.", in M. Bordo \& B. Eichengreen, A retrospective on the Bretton Woods system: Lessons for international monetary reform. University of Chicago Press, 1993. 3-108.

Bordo, Michael D., Barry Eichengreen, and Douglas A. Irwin. 1999, "Is Globalization Today Really Different than Globalization a Hunderd Years Ago?", NBER Working Paper, No.7195.

Bordo, Michael D., and Thomas Helbling. 2003, "Have national business cycles become more synchronized?”. NBER Working paper, No. 10130.

Doyle, Brian M. and Faust, Jon, 2005. "Breaks in the Variability and Comovement of G-7 Economic Growth," The Review of Economics and Statistics, MIT Press, vol. 87(4), pages 721-740, November.

Duval Romain, Nan Li, Richa Saraf and Dulani Seneviratne, 2015, "Value-Added Trade and Business Cycle Synchronization", Journal of International Economics, forthcoming.

Heathcote Jonathan, Fabrizio Perri, 2004, "Financial globalization and real regionalization", Journal of Economic Theory, Volume 119, Issue 1, November 2004, Pages 207-243

Imbs, Jean 2004. "Trade, Finance, Specialization, and Synchronization". The Review of Economics and Statistics. MIT Press, vol. 86 (3), pages 723-734, August.

Ilzetzki, Ethan, Carmen M. Reinhart and Kenneth S. Rogoff, 2015, "Exchange Rate Arrangements Entering the 21st Century: Which Anchor Will Hold?," mimeo, Harvard University, at http://www.carmenreinhart.com/data/browse-by-topic/topics/11/.

Kalemli-Ozcan, Sebnem, Elias Papaioannou, and Fabrizio Perri. 2013, "Global banks and crisis transmission". Journal of International Economics 89.2 (2013): 495-510.

Kalemli-Ozcan Sebnem, Elias Papaioannou and Jose-Luis Peydro 2013. "Financial Regulation, Financial Globalization, and the Synchronization of Economic Activity". Journal of Finance, vol. 68(3).

Kose, Ayhan, Otrok, Christopher, Whiteman, Charles H., 2003. "International business cycles: world, region, and country-specific factors". American Economic Review 93 (4), 1216-1239.

Kose, Ayhan, Otrok, Christopher, Whiteman, Charles H., 2008. "Understanding the evolution of world business cycles". Journal of International Economics 75 (1), 110-130. 
Kose, M. Ayhan, Prasad, Eswar S., Terrones, Marco E, 2003. "How Does Globalization Affect the Synchronization of Business Cycles?". American Economic Review, vol. 93(2), pages 57-62, May.

Kose, M. Ayhan, Prasad, Eswar S., Terrones, Marco E., 2006. "How do trade and financial integration affect the relationship between growth and volatility?". Journal of International Economics, vol. 69(1), pages 176-202, June.

Kose, M. Ayhan \& Yi, Kei-Mu, 2006. "Can the standard international business cycle model explain the relation between trade and co-movement?". Journal of International Economics, Elsevier, vol. 68(2), pages 267-295, March.

Ayhan Kose \& Eswar Prasad \& Kenneth Rogoff \& Shang-Jin Wei, 2006. "Financial Globalization: A Reappraisal". IMF Working Papers 06/189, International Monetary Fund.

Lumsdaine, Robin L. and Eswar S. Prasad. 2003, "Identifying The Common Component Of International Economic Fluctuations: A New Approach". Economic Journal, 2003, Jan 101127.

Monnet, Eric. 2014. "Monetary Policy without Interest Rates: Evidence from France's Golden Age (1948 to 1973) Using a Narrative Approach". American Economic Journal: Macroeconomics, 6(4): 137-69.

Monnet Eric, and Damien Puy, 2015, "Foreign reserves and international adjustment under the Bretton Woods system: a reappraisal", mimeo.

Mumtaz, Haroon, Simonelli, Saverio, Surico, Paolo, 2011. "International co-movements, business cycle and inflation: A historical perspective". Review of Economic Dynamics 14 (1), 176-198.

Obstfeld, Maurice 1994. "Risk-Taking, Global Diversification, and Growth." American Economic Review, 84(5): 1310-1329.

Romer, Christina D., and David H. Romer. 2002. "A Rehabilitation of Monetary Policy in the 1950's ." American Economic Review, 92(2): 121-127.

Rodrik Dani, 1997, “Has globalization gone too far?”. Institute for International Economics, Washington.

Rodrik Dani, 2002, “Feasible Globalizations”, NBER Working Paper No. 9129.

Stock James H. and Watson, Mark W. 2005. "Understanding Changes In International Business Cycle Dynamics," Journal of the European Economic Association, MIT Press, vol. 3(5), pages 968-1006, 09. 
Williamson, John. 1985, "On the system in Bretton Woods". The American Economic Review, 74-79. 


\section{APPENDIX A - Sample and Data}

I. Sample of Countries

\begin{tabular}{|lllll|}
\hline $\begin{array}{l}\text { North } \\
\text { America }\end{array}$ & Continental & Northern & Latin \\
Europe & Europe & Asia & America \\
\hline United States & Austria & United Kingdom & Japan & Mexico \\
Canada & Belgium & Finland & India & Chile \\
& France & Ireland & Pakistan & \\
& Germany & Denmark & & \\
& Italy & Norway & & \\
& Luxembourg & Sweden & & \\
& Netherlands & & \\
& Greece & & & \\
& & & & \\
\end{tabular}

II. Data Sources and Summary Statistics

\begin{tabular}{|c|c|c|c|c|c|c|c|c|}
\hline Variable & Source & Obs & & & Std. Dev. & Min & \multicolumn{2}{|c|}{ Max } \\
\hline Trade integration (as \% GDP) & IFS & & 84 & 24.1 & 23.2 & & 2.3 & 149.6 \\
\hline Financial Integration (as \% GDP) & Lane and Milessi-Ferretti (2006) & & 84 & 914.0 & 3485.9 & & 18.1 & 25129.7 \\
\hline Share of Manufacturing (as \% GDP) & World Bank & & 84 & 21.07 & 6.34191 & & 8 & 41 \\
\hline
\end{tabular}

\section{OECD Quarterly GDP Statistics vs. Industrial Production}

An important drawback of existing empirical work is that official quarterly GDP statistics, which are provided by the OECD, are not available before 1960. As a result, the sample used for estimation excludes two important cycles of the Bretton Woods era (1952-1953 and 1957-1958). Another important issue is that even when available these statistics are, in general, not based on output data (coming either from retail, manufacturing or survey data) but are the result of a linear interpolation, at least until the mid 1980s. In our sample of 21 countries, we find that two thirds of our countries are affected by this procedure which tends to wash out cyclical fluctuations. Figures below illustrate this issue in the case of Greece and Denmark over the period 1960-1972, but similar pictures emerge in at least 10 other countries in our sample. Blue lines report GDP growth derived from (interpolated) OECD statistics. Red lines report growth derived from IP indexes from IMF archival database. 

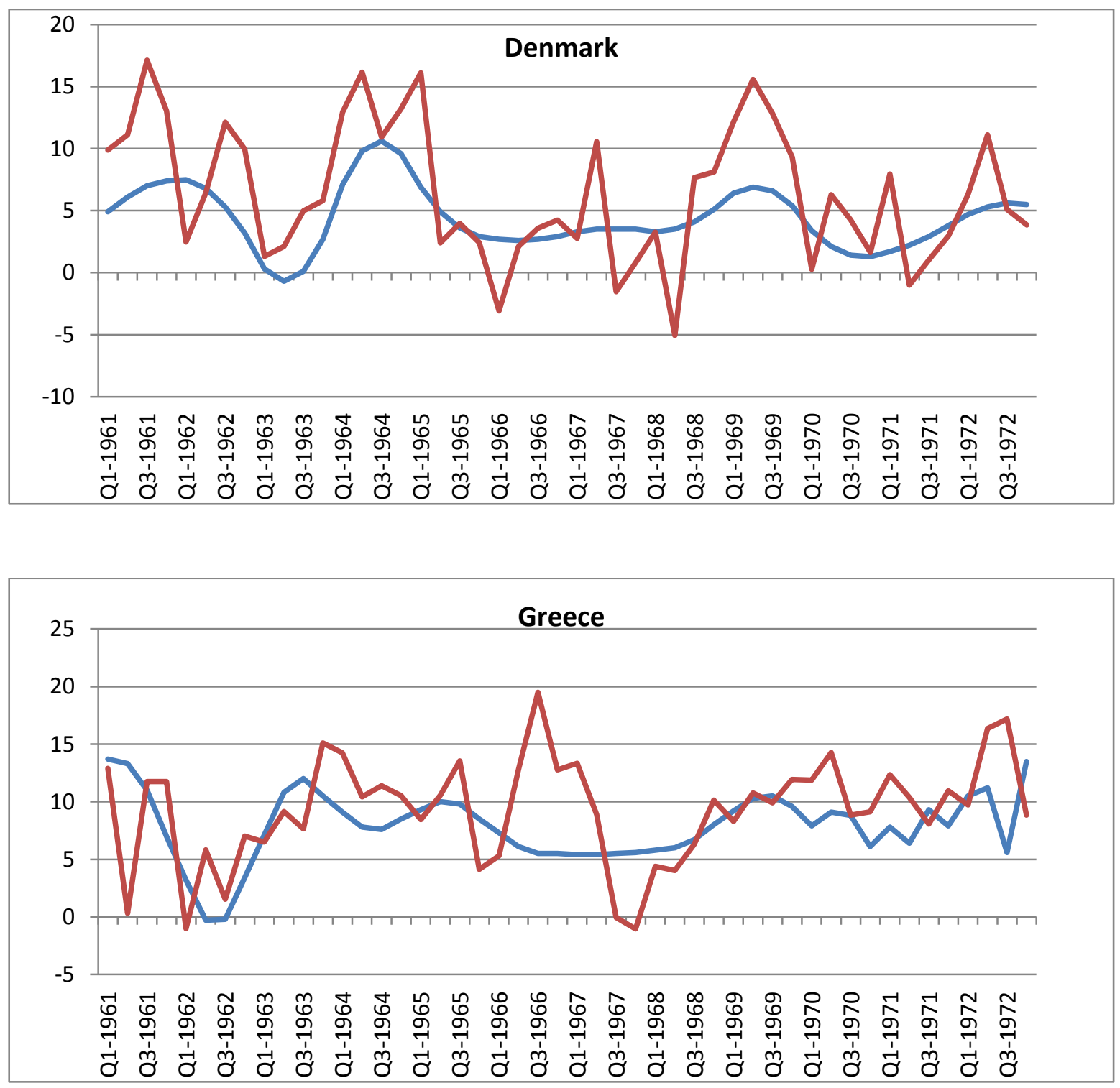

IV. GDP vs. Industrial Production

The plots below compare growth rates obtained using GDP and IP series for the US and France. We find that the series are highly correlated. Over the whole sample period, we find correlations of 0.85 and 0.89 for France and the US, respectively. IP series are computed by the authors using IMF archives as described in the main text. Historical GDP statistics are taken from the BEA for the US and INSEE for France. 
United States - Full Sample (1950 Q1-2014 Q4)

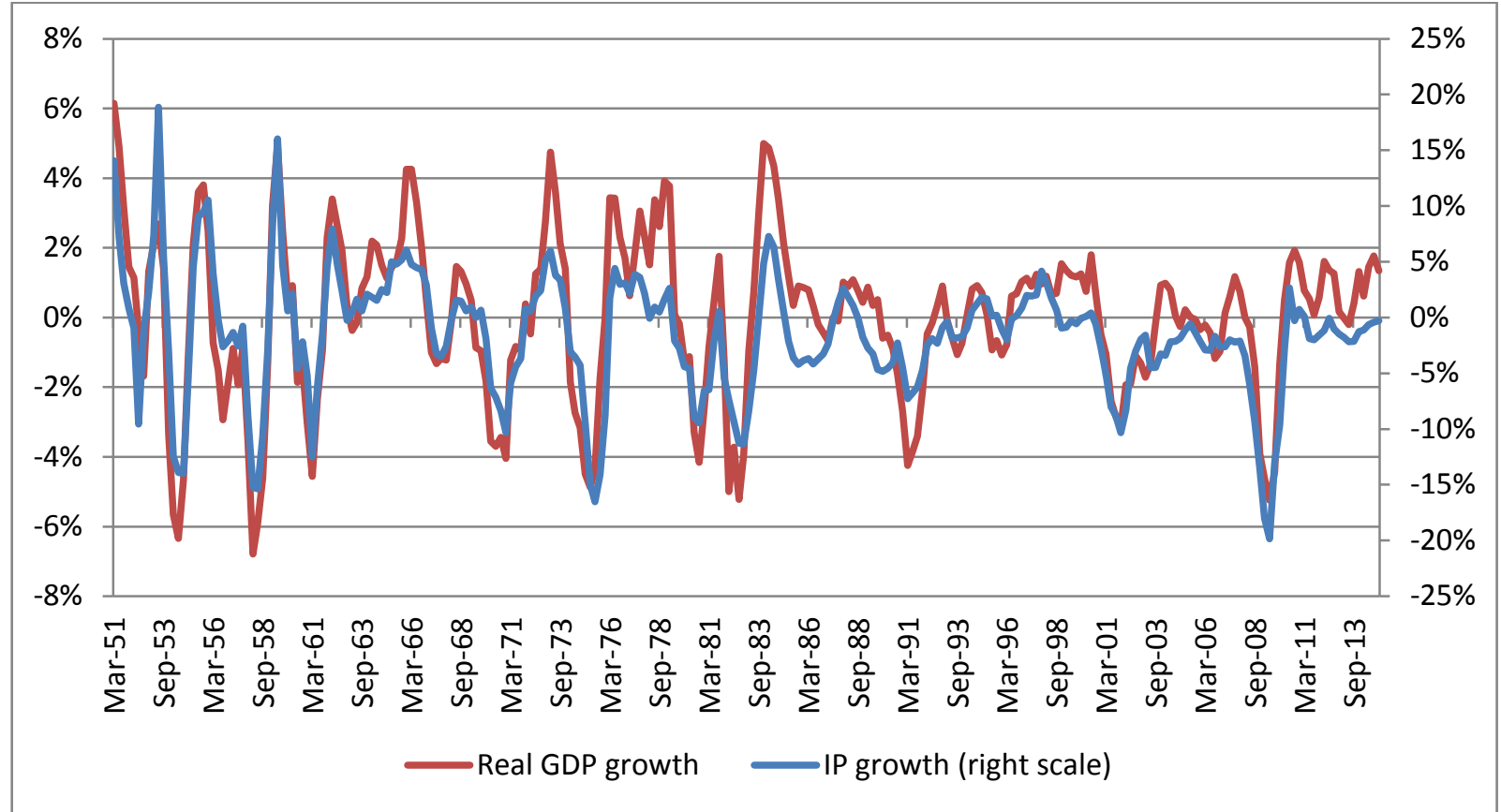

France - Full Sample (1950 Q1-2014 Q4)

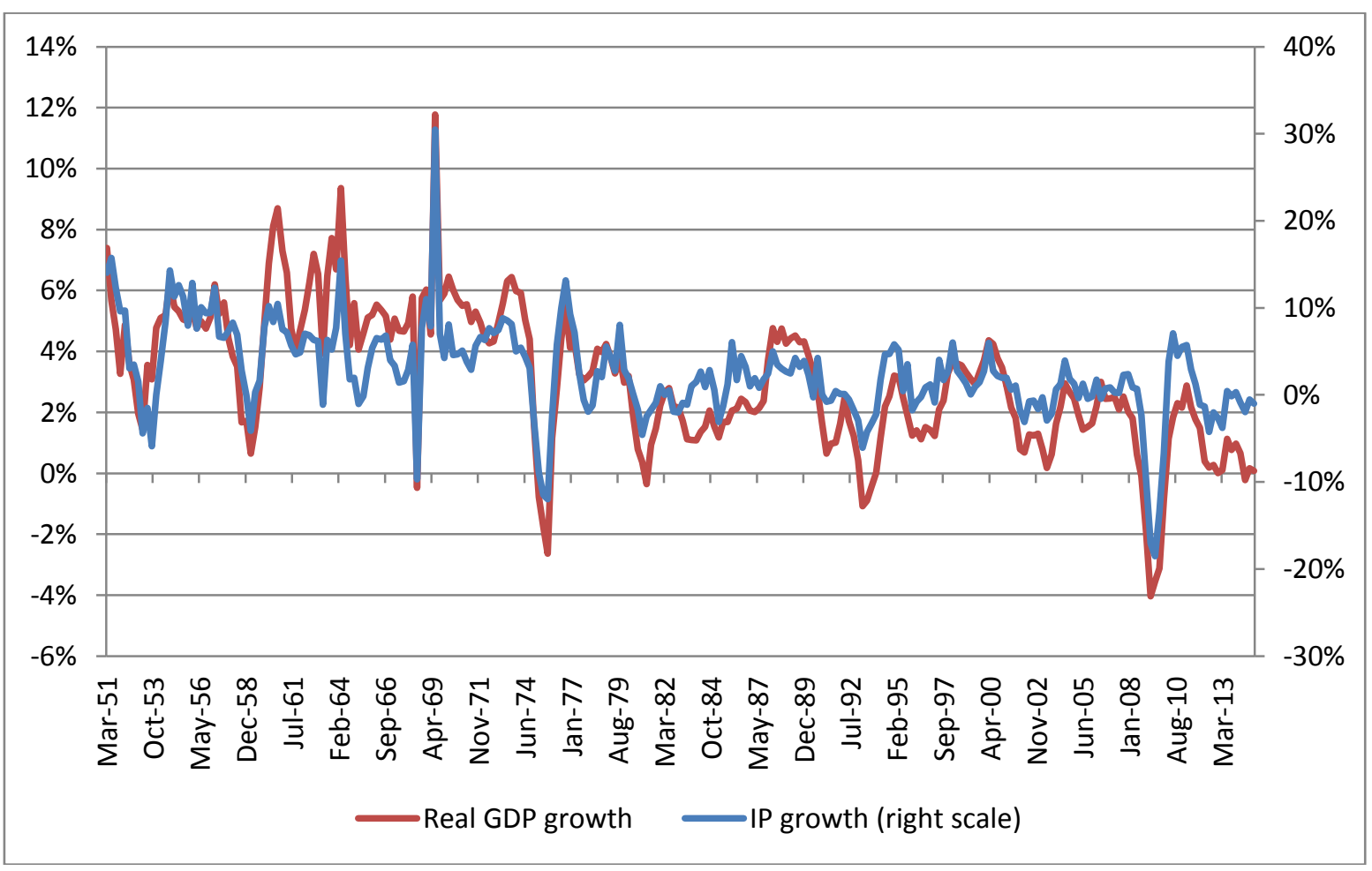




\section{$\underline{\text { APPENDIX B - Supplementary Results }}$}

\section{Factor Estimation and Variance Decompositions: IP vs. GDP}

The figure below compares the shape of the common factor when using GDP growth rather than IP indexes. Over the period 1973-2014, we find that the two common factors are almost identical, confirming that IP indexes are very accurate trackers of real activity. In both cases, the world factor accounts, on average, for $37 \%$ of countries' output variance.

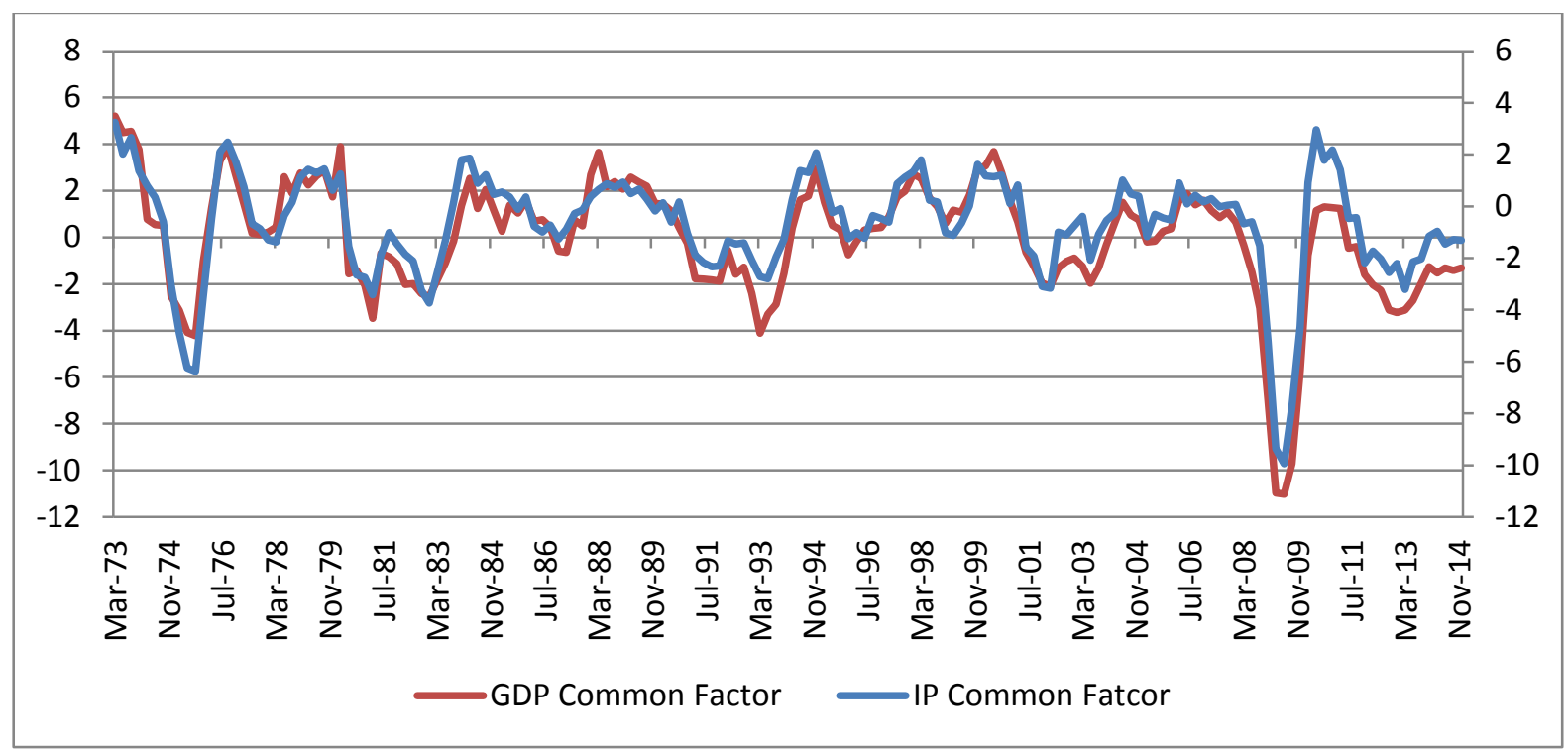

II. Variance decompositions: Comparison with Kose, Otrok \& Whiteman (KOW, 2003)

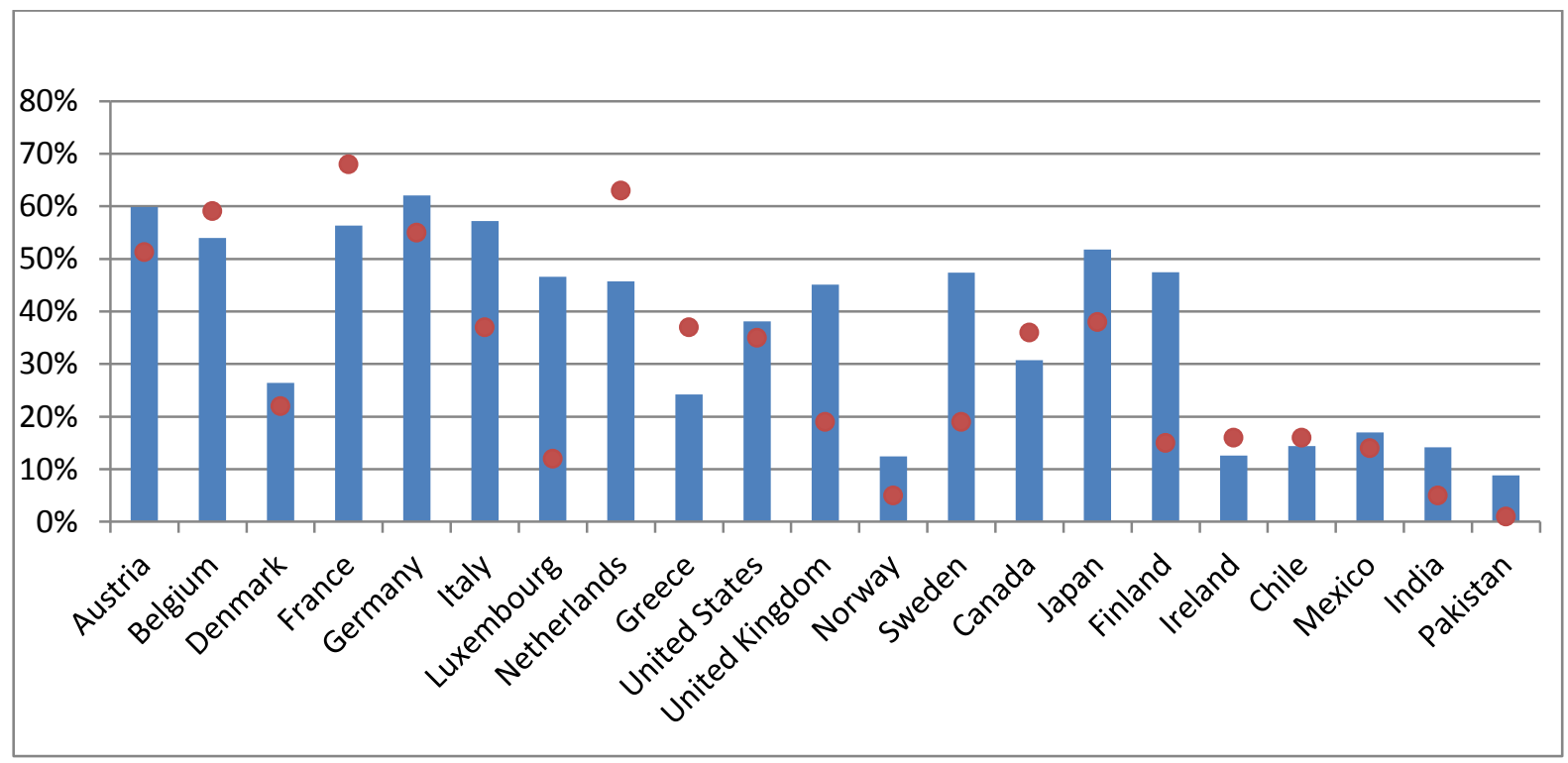

Red dots report the share of variance accounted for by the global factor in KOW (2003). Blue bars report our results when restricting the sample to 1960-1990. Note that the cross section used by KOW is significantly higher (60 countries), which might explain the small discrepancies at the country level. 


\section{Table 2 - Panel Regressions - Extensions}

This table presents the results of the panel estimations with the additional controls discussed in Section 5. In all specifications the dependent variable is the share of variance accounted for by the global factor for country $i$ in period $t$ (plotted in Figure 6). Columns (1) and (2) present results when we measure trade integration using VA trade. Note that because the specialization was not available for Canada, Norway and Pakistan, the sample is smaller. However, the significance of FX regime does not improve when using the full sample (i.e dropping the specialization variable). Overall we find that (i) the coefficients attached to the financial integration variable and its interaction are almost unchanged (ii) the significance of trade integration still depends on the inclusion of EMs.

\begin{tabular}{|c|c|c|c|c|c|c|c|c|}
\hline & $\begin{array}{c}\text { Full Sample } \\
\text { (1) }\end{array}$ & $\begin{array}{c}\text { Advanced } \\
\text { (2) }\end{array}$ & $\begin{array}{c}\text { Full Sample } \\
\text { (3) }\end{array}$ & $\begin{array}{c}\text { Advanced } \\
\text { (4) }\end{array}$ & $\begin{array}{c}\text { Full Sample } \\
\text { (5) }\end{array}$ & $\begin{array}{c}\text { Advanced } \\
\text { (6) }\end{array}$ & $\begin{array}{c}\text { Full Sample } \\
\text { (7) }\end{array}$ & $\begin{array}{c}\text { Advanced } \\
\text { (8) }\end{array}$ \\
\hline Manufacturing & $\begin{array}{l}-101.3 \\
(98.28)\end{array}$ & $\begin{array}{l}87.33 \\
(66.14)\end{array}$ & $\begin{array}{l}-96.95 \\
(82.48)\end{array}$ & $\begin{array}{l}135.7 \\
(116.3)\end{array}$ & $\begin{array}{l}-91.40 \\
(79.99)\end{array}$ & $\begin{array}{l}139.6 \\
(117.1)\end{array}$ & $\begin{array}{l}-94.65 \\
(82.08)\end{array}$ & $\begin{array}{l}134.5 \\
(120.4)\end{array}$ \\
\hline |Financial_Integration & $\begin{array}{l}-0.0934^{* * *} \\
(0.0256)\end{array}$ & $\begin{array}{l}-0.0878^{* * *} \\
(0.0254)\end{array}$ & $\begin{array}{l}-0.103^{* * *} \\
(0.0323)\end{array}$ & $\begin{array}{l}-0.0855^{* * *} \\
(0.0267)\end{array}$ & $\begin{array}{l}-0.111^{* * *} \\
(0.0340)\end{array}$ & $\begin{array}{l}-0.0902^{* * *} \\
(0.0279)\end{array}$ & $\begin{array}{l}-0.105^{* * *} \\
(0.0325)\end{array}$ & $\begin{array}{l}-0.0837^{* * *} \\
(0.0265)\end{array}$ \\
\hline \multicolumn{9}{|l|}{ Time dummies } \\
\hline Oil shocks period (1973-1983) & $\begin{array}{l}18.23 * \\
(10.33)\end{array}$ & $\begin{array}{l}36.69 * * * \\
(9.322)\end{array}$ & $\begin{array}{l}22.05^{*} \\
(10.65)\end{array}$ & $\begin{array}{l}38.60 * * * \\
(9.114)\end{array}$ & $\begin{array}{l}20.29 * \\
(10.95)\end{array}$ & $\begin{array}{l}37.25^{* * *} \\
(9.640)\end{array}$ & $\begin{array}{l}20.85^{*} \\
(10.95)\end{array}$ & $\begin{array}{l}39.72 * * * \\
(10.46)\end{array}$ \\
\hline Globalization (1984-2006) & $\begin{array}{l}-1.446 \\
(11.43)\end{array}$ & $\begin{array}{l}23.51^{*} \\
(11.07)\end{array}$ & $\begin{array}{l}6.033 \\
(11.72)\end{array}$ & $\begin{array}{l}27.41 * \\
(14.93)\end{array}$ & $\begin{array}{l}5.493 \\
(12.12)\end{array}$ & $\begin{array}{l}26.68 * \\
(15.06)\end{array}$ & $\begin{array}{l}5.169 \\
(11.89)\end{array}$ & $\begin{array}{l}28.20 \\
(16.34)\end{array}$ \\
\hline GFC (2007-2014) & $\begin{array}{l}32.97^{*} \\
(19.02)\end{array}$ & $\begin{array}{l}68.14^{* * *} \\
(16.03)\end{array}$ & $\begin{array}{l}41.56^{* *} \\
(16.75)\end{array}$ & $\begin{array}{l}78.00 * * * \\
(18.87)\end{array}$ & $\begin{array}{l}42.08^{* *} \\
(17.37)\end{array}$ & $\begin{array}{l}78.20^{* * * *} \\
(19.44)\end{array}$ & $\begin{array}{l}39.58^{* *} \\
(17.21)\end{array}$ & $\begin{array}{l}79.86 * * * \\
(20.74)\end{array}$ \\
\hline $\begin{array}{l}\text { Interaction term } \\
\text { Financial_Integration*GFC }\end{array}$ & $\begin{array}{l}0.0557^{* *} \\
(0.0239)\end{array}$ & $\begin{array}{l}0.0574^{* *} \\
(0.0237)\end{array}$ & $\begin{array}{l}0.0625^{* *} \\
(0.0274)\end{array}$ & $\begin{array}{l}0.0553 * * \\
(0.0254)\end{array}$ & $\begin{array}{l}0.0703 * * \\
(0.0297)\end{array}$ & $\begin{array}{l}0.0593 * * \\
(0.0268)\end{array}$ & $\begin{array}{l}0.0639 * * \\
(0.0275)\end{array}$ & $\begin{array}{l}0.0539 * * \\
(0.0245)\end{array}$ \\
\hline \multicolumn{9}{|l|}{ Additional Controls } \\
\hline Trade_Integration (VA trade) & $\begin{array}{l}2.837 \\
(1.755)\end{array}$ & $\begin{array}{l}0.302 \\
(1.590)\end{array}$ & $\begin{array}{l}2.478 \\
(1.946)\end{array}$ & $\begin{array}{l}0.0815 \\
(1.722)\end{array}$ & $\begin{array}{l}2.331 \\
(1.785)\end{array}$ & $\begin{array}{l}0.126 \\
(1.762)\end{array}$ & $\begin{array}{l}2.364 \\
(1.958)\end{array}$ & $\begin{array}{l}0.124 \\
(1.704)\end{array}$ \\
\hline Specialization & & & $\begin{array}{l}213.4 \\
(153.7)\end{array}$ & $\begin{array}{l}-171.7 \\
(281.7)\end{array}$ & $\begin{array}{l}257.6 \\
(166.3)\end{array}$ & $\begin{array}{l}-155.3 \\
(274.3)\end{array}$ & $\begin{array}{l}214.9 \\
(160.4)\end{array}$ & $\begin{array}{l}-168.8 \\
(285.9)\end{array}$ \\
\hline $\begin{array}{l}\text { FX regime } \\
\text { (original classification) }\end{array}$ & & & & & $\begin{array}{l}0.786 \\
(0.783)\end{array}$ & $\begin{array}{l}0.387 \\
(0.632)\end{array}$ & & \\
\hline $\begin{array}{l}\text { FX regime } \\
\text { (adjusted for Euro Countries) }\end{array}$ & & & & & & & $\begin{array}{l}0.436 \\
(0.980)\end{array}$ & $\begin{array}{l}-0.319 \\
(1.245)\end{array}$ \\
\hline constant & $\begin{array}{l}17.17 \\
(24.50)\end{array}$ & $\begin{array}{l}1.639 \\
(28.01)\end{array}$ & $\begin{array}{l}8.275 \\
(24.85)\end{array}$ & $\begin{array}{l}5.315 \\
(27.05)\end{array}$ & $\begin{array}{l}1.847 \\
(25.01)\end{array}$ & $\begin{array}{l}1.017 \\
(27.52)\end{array}$ & $\begin{array}{l}7.023 \\
(25.53)\end{array}$ & $\begin{array}{l}6.139 \\
(28.37)\end{array}$ \\
\hline$N$ & 80 & 64 & 68 & 56 & 68 & 56 & 68 & 56 \\
\hline R-sq & 0.680 & 0.741 & 0.729 & 0.797 & 0.734 & 0.798 & 0.730 & 0.797 \\
\hline
\end{tabular}




\section{$\underline{\text { APPENDIX C }}$}

\section{NARRATIVE APPROACH OF THE WORLD ECONOMIC CYCLE}

This section relies on IMF annual reports published from 1950 to 2014 to explain the movements in the world cycle computed in Section IV (Figure 3). Our goal is twofold: first we want to know whether the cycles and their turning points were indeed observed, and characterized as such, by contemporary economists analyzing the global economy. Second, we want to highlight the main factors and determinants of these cycles, as perceived by the IMF at that time. When available, we also report information on which countries were affected and how the transmission worked. For each cycle, we compare the dates of the peaks and troughs of the cycle that we calculated to the analysis presented in the IMF annual reports. Although we want to provide only a short narrative of the main economic cycles, we quote extensively the reports when relevant.

The rationale for relying on IMF annual reports is to track a continuous and consistent source, which was available for the whole postwar period and whose goal was to analyze the conditions of the global economy (including the so called "less developed", "developing economies" and "emerging markets"). Analyses published in IMF annual reports over 70 years provide a natural starting point for a narrative of the world economic cycle. Note that IMF annual reports are published in April. Thus, the 1970 report, for example, present analysis on the period 1969 Q2 to 1970 Q1. As the analysis below makes clear, there were few comments on the common cycle of emerging markets before the 1970s as the "industrialized economies" provided the bulk of world output's fluctuations.

We also compare the peaks and troughs of the world cycle to US cycles identified by the NBER. This allows us to check whether the US economic cycle has been a systematic driver of the world business cycle since 1950 .

The main conclusions of our narrative analysis based on IMF reports are the following:

1) The cycles of world output growth described in IMF annual reports exactly match the cycles that we identified in Section IV (Figure 3). Estimated expansions and slowdowns as well as the peaks and troughs were clearly characterized as such by IMF reports.

2) World economic cycles were present since 1945, in all decades, and were considered as such by contemporaries - including during Bretton Woods. Narrative evidence also corroborates the fact that co-movement between countries was stronger during the 1970s (with the exception of the US expansion in 1976-1977) and since 2007. We find that the two decades between 1950-1970 and 1980-2005 saw outliers or divergence in the timing of growth for some countries. 
3) We do not find any systematic lead of the US over the world business cycle during the seven decades following World War II. There were however several episodes when the US cycle was viewed as one of the main determinants of the path of the global cycle (1960-1961; 1979-1982; 1984-1986; 1999-2002). This unstable link can be seen in the figure below, which plots the world cycle (estimated in the paper) against US NBER recessions.

4) Except for common supply shocks (in the 1970s) and for the 2007 Global Financial Crisis, co-movements are usually explained by synchronized domestic cycles in which monetary policy is presented as a key driver. Typically, an expansion of output, partly caused by expansionary monetary policy, would increase inflation until restrictive monetary policy is implemented and decreases output etc...These domestic cycles are reinforced by trade linkages which amplified co-movements in aggregate demand.

5) There were more financial shocks after the mid-1980s than ever before, but this did not increase co-movement of output before the global financial crisis of 2007.

6) Starting in the 1970s, the IMF gave more information on the economic cycle of emerging economies. The world cycle started to be more affected by fluctuations outside of the OECD countries, but we do not find evidence in IMF annual reports that the emergence of more economic powers affected significantly (positively or negatively) the degree of co-movement across "industrialized countries".

\begin{tabular}{|l|l|}
\hline US peaks & US troughs \\
\hline 1953 Q2 & 1954 Q2 \\
1957 Q3 & 1958 Q2 \\
1960 Q2 & 1961 Q1 \\
1969 Q4 & 1970 Q4 \\
1973 Q4 & 1975 Q1 \\
1980 Q1 & 1980 Q3 \\
1981 Q3 & 1982 Q4 \\
1990 Q3 & 1991 Q1 \\
2001 Q1 & 2001 Q4 \\
2007 Q4 & 2009 Q2 \\
\hline
\end{tabular}

\begin{tabular}{|l|l|}
\hline World peaks & World troughs \\
\hline 1951Q1 & 1952 Q2 \\
1955 Q1 & 1958 Q2 \\
1960 Q1 & 1963 Q1 \\
1964 Q1 & 1967 Q3 \\
\hline
\end{tabular}




\begin{tabular}{|c|c|}
\hline 1969 Q1 & 1971 Q1 \\
\hline 1973 Q1 & $1975 \mathrm{Q} 2$ \\
\hline 1976Q3 & 1978Q1 \\
\hline 1979 Q1 & $1981 \mathrm{Q} 1$ \\
\hline 1981 Q3 & 1982 Q4 \\
\hline 1984 Q1 & 1986 Q4 \\
\hline 1988 Q4 & 1993 Q2 \\
\hline 1994 Q4 & 1995 Q4 \\
\hline 1998 Q1 & 1999 Q1 \\
\hline 1999 Q4 & 2002 Q1 \\
\hline 2006 Q1 & 2009 Q2 \\
\hline $2010 \mathrm{Q} 2$ & $2013 \mathrm{Q}$ \\
\hline
\end{tabular}

\section{World Cycle vs. US recessions (shaded areas)}

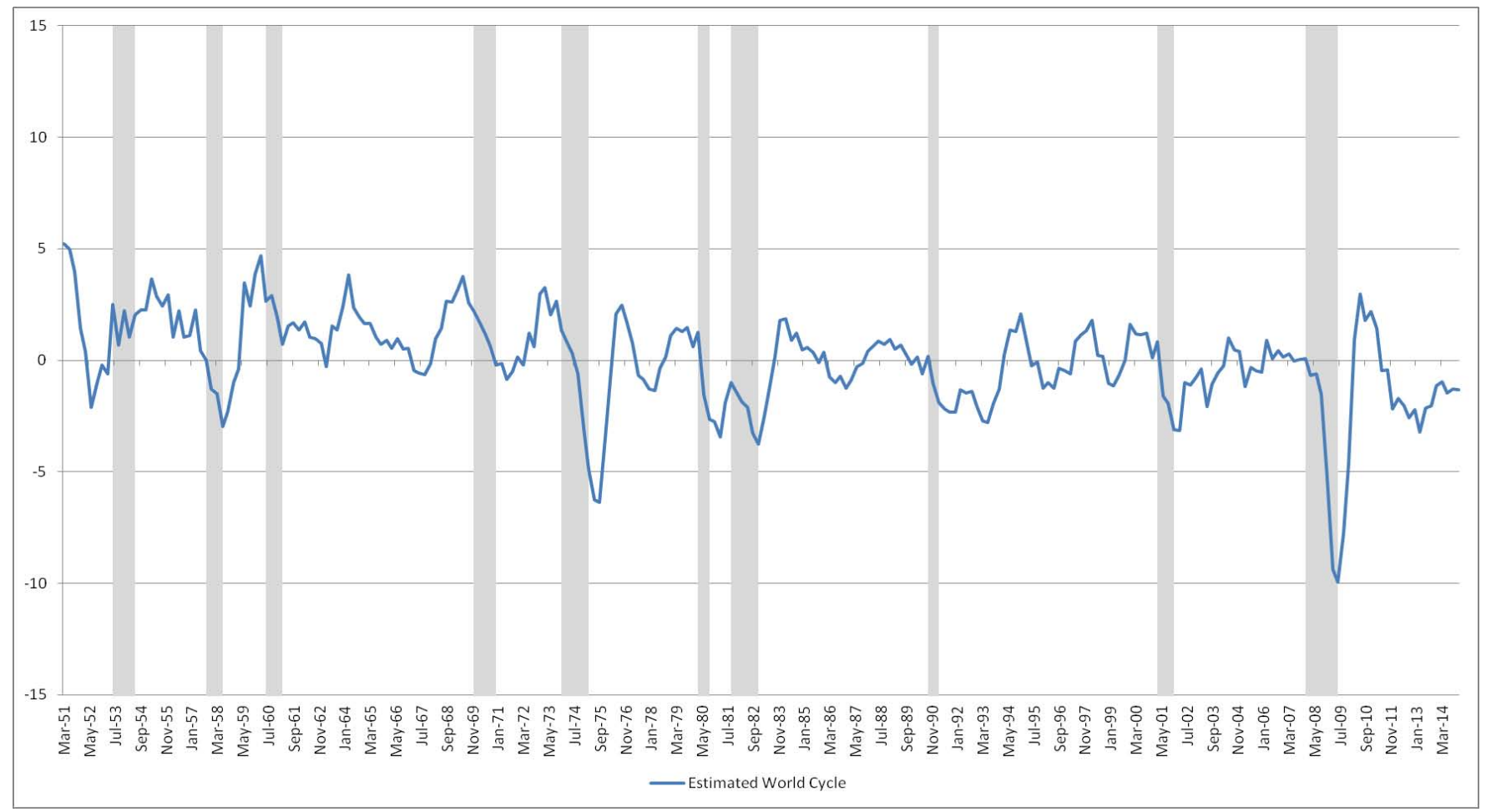

\section{1) Peak: 1951 Q1 ; Trough: 1952 Q2}

In 1950, industrialized countries experienced high growth of industrial output. The factors that contributed to this upward cycle were the devaluations of September 1949 in Western Europe which led to an increase in exports, as well as the postwar restoration of production capacity. After the outbreak of the Korean war, in June 1950, a wave of rearmament followed in the Western world. Preparations for extensive rearmament programs boosted demand, but 
also commodities and raw material prices, as well as imports, both in the US and Western Europe. The 1952 IMF annual reports states that:

"U.S. imports, which even before the outbreak of fighting in Korea were rising, showed a further prompt and vigorous increase after the conflict began; this increase dominated the first phase of the reactions to the Korean outbreak through the first quarter of 1951. [...] The first quarter of 1951 thus marked the end of the initial reaction to the outbreak of fighting in Korea. By the second quarter, U.S. imports had turned down and the decline in commodity prices had begun." (IMF annual report, 1952, p.1)

The reason for the 1951 downturn was that most countries had implemented restrictive monetary policy in the second half of 1950 in response to world increase in prices:

"The instruments of monetary policy have been used more widely during the past year [1951], particularly in the industrial countries of Europe and North America, to cope with the resurgence of inflationary pressures (IMF annual report, 1952, p. 28)”.

The policy stance had a deflationary effect on prices and output and, in April 1952, the IMF report observed that there was a "clear tendency toward easing credit". In the third semester of 1952, world output was growing again.

\section{2) Peak: 1955 Q1 (sharp fall starts in 1957 Q2) ; Trough: 1958 Q2}

After 1952, the trend toward more expansionary policies continued in most countries:

"In 1953 and early 1954 a number of countries relaxed the anti-inflationary monetary and fiscal policies which they had adopted after the outbreak of hostilities in Korea in mid-1950. These changes reflected a recognition that an expansion of home demand for both consumer goods and investment could be safely allowed and, in some countries, that an increase in demand was in fact needed to combat unemployment. The easing of credit restrictions marked a new phase of the more active monetary policy which many countries had adopted in 1950 and 1951 as a brake on inflation." (IMF annual report, 1964, p.62)

In contrast, US monetary policy turned back to a restrictive stance as soon as 1953 to fight inflation. An important de-synchronization between the US and other industrialized countries followed in 1953-1954 as monetary policy stance differed, and the US experienced a mild and brief recession in 1953-1954 (peak in 1953 Q2 and trough in 1954 Q2, according to the NBER). Effects of the US recession were however offset by the boom of European countries, such that world trade continued to expand and the world cycle remained upward until 1955: 
"Even more surprising than the absence of any important effect of the North American recession of 1953-54 on economic activity elsewhere is the slightness of its repercussions on the over-all payments situation. The conjunction of a downswing in the dollar area with an upswing in non-dollar industrial areas might have been expected to curtail world trade and to cause a recrudescence of payments difficulties in the non-dollar world. In fact, the value of world trade increased throughout 1953 and 1954." (IMF annual report, 1955, p. 13)

In the second semester of 1954, the US joined the other countries in a pattern of cheap credit and high growth, until the stance of monetary policy changed again. Thus, beginning in 1955 Q1, there was a synchronized tendency toward monetary restrictions and lower growth:

"By the beginning of 1955, however, this consistent pattern was no longer maintained. Interest rates were rising in many developed countries as governments attempted to moderate new expansionary pressures [...] Believing the tendency toward expansion to be excessive, monetary authorities in most countries took action to limit the increased demand (IMF annual report, 1955, p. 62- 64)”.

Throughout 1955 and 1956, monetary policy remained only mildly restrictive and, although the global cycle had reached a plateau, there was no sharp fall in world output. During these years, the IMF also noticed important differences across countries in the magnitude of monetary restriction and in output growth (Japan for example was still booming). But everywhere, prices continued to increase. As a consequence, monetary policies became even more restrictive in 1957 :

"The story of the year is to a large extent a record of the endeavors of governments and central banks, and to some extent of responsible leaders in trade unions and other economic organizations, to devise and apply suitable means for dealing with the recurrent problem of inflationary pressure (IMF annual report 1957, p. 74)”.

In 1957, speculative attacks against exchange rate parity (in France and Italy), as well as the Suez crisis, contributed further to downward pressures on output. The deflationary impact of monetary policy restrictions was not uniform across countries; recessions happened sequentially throughout 1957 and the first half of 1958. They were followed by new waves of monetary expansion which set the path for recovery in early 1958 :

"Around the middle of 1957 recessionary tendencies became increasingly evident in some industrial countries; but in many of them expansion still continued in early 1958." (IMF annual report 1958, p. 58) 
"Countries that had not begun to feel the recession continued their restrictive monetary policies in early 1958. Other countries where economic activity had fallen off sought to revive demand by encouraging bank credit expansion (IMF annual report 1958, p. 65)"

"The authorities in practically all the more industrialized countries were confronted in 1958 with the problem of checking the slackening of activity and inducing a renewed expansion without sacrificing the objective of price stability. This task was made more difficult nearly everywhere by the fact that prices, though rising more slowly than before, had not entirely leveled off. On the other hand, the adoption of antirecession measures was facilitated in most of these countries by favorable balance of payments conditions." (IMF annual report 1959 p. 68)

According to the NBER, the US recession - the strongest since 1945 - also had its trough in 1958 Q2.

\section{3) Peak: 1960 Q1 ; Trough: 1963 Q1}

The 1960-1963 cycle was milder than the previous one and monetary policy played a minor role in explaining the downward phase. Besides a general co-movement in the boom phase in 1959 and a global early slowdown in 1960, this cycle featured was marked again by different timing across countries:

"Initially, the United States led the other industrial countries in the economic expansion that followed the 1957-58 recession. However, after mid-1959 the rise in economic activity became more vigorous in Europe and Japan, and early in 1960 the expansion was halted in the United States, whereas it continued in most of the other industrial countries. [...] In several European countries (for example, Italy, the Netherlands, and Norway), the growth of production tended to diminish as the year advanced, and in a few (for example, Denmark and the United Kingdom) it ceased. (IMF annual report 1961 p. 45)"

According to the IMF, the rise in production in both continental Europe and Japan was largely attributable to an increase in productivity resulting from substantial investments in previous years. After the slowdown of 1960, the sequence changed however with a shortlived moderate expansion in 1961 in North America and few countries but a slowdown in others:

"The year 1961 was one of general expansion in the industrial countries. In the United States and Canada, industrial production and real national product resumed their upward course during the spring of 1961, following the mild recession of 1960. Expansion continued in Europe and Japan, although at a slower rate than in the earlier year, as production 
approached the limits of the available supplies of labor and, in some countries, investment demand became less insistent." (IMF annual report 1962 p. 1)",

Production finally slowed down globally in 1962.

"World industrial production (excluding that in the U.S.S.R. and other eastern bloc countries) continued to rise during 1962, although at a slower rate than in 1961. A reduced rate of growth was apparent both in North America (United States and Canada) and in most countries in continental Europe, while production remained sluggish in the United Kingdom, and output in Japan, after a record rise for several years, suffered a decline in the second half of 1962 " (IMF annual report 1963 p. 3)"

In the downward world cycle of 1960-1963, monetary policy played a minor role, contrary to the previous recession. According to the IMF, domestic cycles were mostly determined by shortages of capacity, and then downward cycles transmitted to other countries through trade. The downward spiral stopped in 1963:

"In contrast to other recent years, when there were significant exceptions, output expanded during 1963 at a satisfactory rate in all the industrial countries. (IMF annual report 1964 p. 3)"

\section{4) Peak: $1964 \mathrm{Q1}$; Trough: $1967 \mathrm{Q3}$}

The rapid expansion of output in 1963 stopped in early 1964 because of monetary policy measures which had been implemented to mitigate the inflationary effect of output growth on prices:

"Within 1964 there was a slowing down of economic activity in several major countries, and the rate of increase in world trade was somewhat lower than during the preceding year, although still substantial. [...] Some slowing down in economic growth was perhaps to be expected after the exceptionally rapid rise in production that took place in virtually all the industrial countries during 1963. It is probably unavoidable that from time to time countries will find it necessary to introduce temporary measures of restraint to maintain internal and external stability. Indeed, some progress was made in 1964 in containing upward pressures on prices and wages where these had been excessive." (IMF annual report, 1965, p. 1-2)

In early 1964, there was however a difference between North America, which did not experience a significant slowdown, and the rest of the world. Still, the downward cycle continued in 1966:

"The year 1966 was one of adjustment for the world economy-an adjustment that has yet to

run its course. For the year as a whole compared to 1965, industrial production and 
international trade on a world-wide basis again expanded substantially. However, in the course of 1966 the expansion exhibited a marked deceleration. The major cause of this lay in three developments that affected many industrial countries, though with differing importance among them: limitations on further output growth imposed by capacity shortages, some weakening in the underlying forces of expansion, and measures of financial restraint taken early in 1966 to alleviate inflationary pressures". (IMF annual report, 1967, p. 1)

Again, monetary policy had played an important role in influencing the cycle, in the downward phase of 1966 and early 1967:

"During most of 1966, therefore, monetary restrictiveness was the dominant feature of national economic policy in the majority of the industrial countries." (IMF annual report, 1967, p. 5)

as well as in the upward phase of recovery in late 1967:

"The slowdown in the tempo of economic activity in major industrial countries during the latter part of 1966 continued in the first half of 1967, and was accompanied by a shift of national economic policies toward expansion." (IMF annual report, 1968, p. 1)

This shift of policies toward expansion led to a recovery in the second semester of 1967:

"The recovery of economic activity in industrial countries that began around the middle of 1967 engendered a strong resurgence of growth in world output and trade toward the end of the year and in the first part of 1968." (IMF annual report, 1968, p. 3)

\section{5) Peak: 1969 Q2 ; Trough: 1971 Q2}

After almost two years of rapid expansion of output and trade starting in 1967Q3, inflation was high and current account deficits had worsened (creating speculative attacks against exchange rate parity in some countries such as France, United States and West Germany):

"Rapid expansion and financial imbalance were the main features of the performance of the world economy during 1968 and the first half of 1969. Output and trade in the industrial countries registered a sharp advance, imparting economic stimulus to the primary producing countries; at the same time, inflationary pressures intensified. Several of the industrial countries encountered severe balance of payments difficulties, and the international financial scene was marred by recurrent crises in foreign exchange markets." (IMF annual report, 1969, p. 3)

As a consequence, monetary policy restrictions were again applied to combat inflation and/or balance of payment deficits in 1969. In the second half or 1969, world output was slowing 
down. Restrictive policy effects were even stronger on output during the year 1970, but their impact on prices was small:

"In the first part of 1970, a dominant feature of world economic developments was the continuation of rapid and widespread inflation in industrial countries, where prices advanced at an average rate even higher than during 1969 and wage settlements were far in excess of the trend growth in productivity. At the same time, the over-all growth of real GNP in the industrial countries showed a further deceleration; this was attributable to a small decline of output in the United States and some slowing of the pace of expansion in a number of other countries because of the narrowing or disappearance of spare capacity and the effects of restrictive financial policies. "(IMF annual report, 1970, p. 4)

The downward cycle stopped in 1971 Q2, mostly as a result of "easier demand-management policies" (IMF annual report 1971, p.6 \& p.81), which started in the US and Canada. The shift towards expansionary monetary and fiscal policies led to output growth but forced the US to close the "gold window" and put an end to the system of Bretton Woods.

\section{6) Peak: 1973 Q1 ; Trough: 1975 Q2}

The upward cycle of output reached a peak in early 1973, before the oil shocks. According to the IMF, monetary policy and full absorption of slack explained, again, the synchronized cycle in most countries:

"Even before the abrupt change in the oil situation late in 1973, a marked slowing of output expansion in the industrial countries was clearly under way and was expected to extend into the first half of 1974. In most of these countries, absorption of the slack in resource utilization that developed during the 1970-71 slowdown had progressed far enough by mid1973 to force a tapering of the rate of growth in total output toward closer conformity with the longer-run growth rate of productive capacity. Moreover, the high rates of price inflation that accompanied the expansion of economic activity during the latter part of 1972 and early 1973 had led the authorities of many industrial countries to introduce or tighten policies of financial restraint, and the impact of such policy actions on real activity had clearly begun to take effect in some of the larger countries." (IMF annual report, 1974, p. 2)

The increase in oil prices decided by the OPEC in the last semester of 1973 created a large supply shock that decreased output by a magnitude never reached since the end of World War II. The recession spread worldwide through trade and capital markets, although the impact on emerging markets was weaker.

According to the IMF, "the deep and prolonged international recession that started late in 1973 reached its low point in the first half of 1975. ” (IMF annual report, 1976, p. 3) 
Starting mid-1975, the recovery began because of expansionary policy designed to fight the crisis. But they did not solve the inflation problem and thus created the conditions for a new cycle of restrictive monetary policy that started in the second half of 1976:

"At mid-1976, the world economy was completing the first year of recovery from its most severe recession in four decades. Production in the industrial countries was again expanding at a satisfactory pace, and rates of inflation were considerably below those experienced in 1974 and the first half of 1975. By past standards, however, both unemployment and inflation remained exceptionally high for the early phase of a cyclical upswing. Although demand and output were not rising fast enough to reduce unemployment and excess industrial capacity over the short term to levels considered acceptable by the authorities of most countries, the expansion was sufficiently brisk to arouse widespread concern about the risk of renewed acceleration of price increases. Cautious management of aggregate demand was thus essential for the purpose of bringing down inflation and eliminating inflationary expectations. A number of the major industrial countries were in the process of withdrawing some part of the fiscal stimulus that had been applied during 1975 to combat the recession. Similarly, monetary authorities in those countries were shifting toward somewhat more restrained provision of liquidity to their respective banking systems." (IMF annual report, 1976, p. 1)

\section{7) Peak: 1976 Q3 ; Trough: 1978 Q1}

The IMF acknowledged that the recovery from the previous crisis stopped in the second half of 1976. As described above (cf. IMF annual report, 1976, p. 1), monetary and fiscal policies also turned less expansionary in order to curb inflation and thus had a deflationary effect on output:

"At mid-1976, it was generally anticipated that cyclical recovery in the industrial countries would continue at a satisfactory pace in the latter part of the year. Moderation in the rate of economic expansion during the second half of 1976 was to be expected as the inevitable product of a further working of cyclical forces, but the degree of moderation that actually occurred was surprising. Another factor in the slowdown of economic activity in the second half of 1976 was that fiscal policies in a number of the industrial countries were evidently less stimulative than had been expected. " (IMF annual report, 1977, p. 2)

"As regards fiscal policy, shifts toward withdrawal of at least part of the stimulus provided in 1975 occurred in most of the industrial countries in 1976, and sizable further shifts in the same direction are occurring in some of them during 1977. " (IMF annual report, 1977, p. 6)

CInternational Monetary Fund. Not for Redistribution 
However, the US did not experience such a slowdown, and stood as an outlier during this cycle. The NBER does not record any recession during this period. Emerging markets were also isolated from this cycle:

"The second half of 1976, however, was marked by an unexpected slowdown, and the pickup that followed this worrisome pause proved to be generally weak and short-lived. By the second half of 1977, the European industrial countries had lost virtually all of their previous upward momentum; only the United States, among the larger industrial countries, was achieving a rate of output expansion sufficient to reduce economic slack." (IMF annual report, 1978, p. 3)

In early 1978, world output had reached a bottom: a noticeable recovery began in Western Europe and Japan, pulled by US demand and new shift of policies toward expansion of aggregate demand:

"Despite this picture of sluggish overall growth rates in the industrial countries, some welcome changes occurred in the pattern of expansion of real domestic demand in 1978. They represented a partial reversal of the movements in 1976 and 1977, when the combination of a relatively high rate of expansion in the United States and markedly lower rates among the other industrial countries, especially Japan and the Federal Republic of Germany, became an important source of imbalance in international payment" (IMF annual report, 1979, p. 3)

\section{8) Peak: 1979Q1; Trough: 1982Q4}

The world expansion in 1978, which had fueled the inflation of consumer prices, led governments to implement fiscal and monetary measures of restriction. It was first done in the United States - where expansion of output had been continuous since 1976 - as soon as 1978. Other countries followed in late 1978 or early 1979. As a consequence, the world cycle reverted in the first quarter of 1979, pulled by the slowdown of the US economy:

"In the United States, the pace of domestic demand expansion dropped to an annual rate of less than 1 per cent in the first half of the year 1979; a decline in the rate of U.S. economic expansion had been generally expected and was desired by the authorities in view of the high level of resource utilization and the worsening of domestic inflation. In many other industrial countries, the recovery of domestic demand has continued apace and was particularly marked in the latter part of 1978. (IMF annual report, 1979, p. 3)

"In 1978, the slowdown in the United States was just offset by the pickup of recovery in the rest of the industrial world. Such a balancing of changes, however, has probably come to an end in 1979. The continuing deceleration in the growth rate of the United States, together 
with a leveling off in the pace of expansion in the other large industrial countries, resulted in overall growth of only about 2\% per cent, at an annual rate, in the first half of 1979 for the whole group of industrial countries". (IMF annual report, 1980, p. 3)

In January 1979, the Iranian revolution caused a sharp increase in oil prices, which made the matters worse. Because of the decrease of imports by industrialized countries and of rising oil prices, the recession transmitted to (non-oil producers) emerging markets:

"This tendency toward increasing sluggishness should become somewhat more pronounced during the remainder of 1979 as the adverse effects on real demand that may be expected to emanate from the current surge in oil prices and from inflation more generally begin to be felt." (IMF annual report, 1980, p. 3)

From early 1979 to early 1980, the world recession was noticeable:

"During the period from the beginning of 1979 to the middle of 1980, the world economic situation was marked by three disturbing features. Rates of inflation in most countries remained very high and, indeed, accelerated; growth of real output in the industrial countries began to slow down markedly, threatening to halt the expansion of world trade and to turn into another international recession; and large surpluses and deficits reemerged in the external balances on current account for major groups of countries, giving rise to widespread concern about the ability of some countries, particularly in the non-oil developing group, to sustain the financing of current account deficits on the scale projected. In varying degrees, the more than doubling of oil prices after the end of 1978 was a major factor in all three of these disturbing elements in the global economic picture." (IMF annual report, 1980, p. 5)

Contrary to the previous shocks of the 1970s, governments decided that they could not react to these changes in output by shifting again to expansionary fiscal or monetary policy. The reason was that inflation rates were too high and regarded as not sustainable anymore. According to the IMF report, this was already clear in early 1979, before Paul Volcker took office as chairman of the Federal Reserve:

"On a matter of general relevance, as already noted, the policy reaction to the deflationary impact of the 1979 increases in oil prices may be expected to vary widely among countries, but many countries with relatively high rates of inflation will undoubtedly decide to accept it, rather than to offset it. Any offsetting adjustments of the fiscal stance should not be allowed to compromise targets with respect to the monetary aggregates." (IMF annual report, 1979, p. 9) 
The turn to more restrictive policies, and the priority given to the fight against inflation, was the main characteristics of the period 1979-1981 in all OECD countries. The deflationary impact on output and inflation was strong and immediate, both in advanced and emerging countries.

"Financial policies throughout the industrial world during 1980 and the first half of 1981 were directed toward controlling inflation. This thrust had already become dominant in 1979. As in 1979, the brunt of the anti-inflation thrust of policies in 1980 and the first half of 1981 was borne by monetary policy. This emphasis was most apparent with respect to interest rates, which reached record levels in most industrial countries, first in the spring of 1980 and again a year later. While the rise in interest rates had much to do with financial developments in the United States, it also reflected the rise in inflationary expectations and the tightening of monetary policy in other countries." (IMF annual report, 1981, p. 3)

"The duration of the current slowdown in economic activity has been to a considerable extent a by-product of the restrictive anti-inflation policies pursued by national authorities in the industrial countries since 1979. It has also reflected the corrosive effects of the inflation itself on real incomes and expenditures, along with the deflationary effects on oil importing countries exerted by the 1979-80 increases in oil prices. These developments resulted in a marked flattening of the growth of real disposable income, with consequent effects on aggregate demand." (IMF annual report, 1982, p. 7)

As the deflationary process continued in 1981, there were nevertheless differences appearing in the timing and direction of short term changes in economic activity in the major industrial countries:

"For the United States and Canada, the profile is clearly one of recession during the first half of 1980, recovery over the period through about mid-1981, and renewed recession through at least the first quarter of 1982. In Europe, on the other hand, output has remained relatively stable at about the level to which it had receded by mid-1980." (IMF annual report, 1982, p. 8)

In the US, according to the NBER, there was a trough in 1980 Q3, a peak in 1981 Q3 and another trough in $1982 \mathrm{Q} 4$. The recession continued through 1982. By the end of the year 1982, inflation had decreased enough in most OECD countries such that consumer confidence was restored and monetary policies shifted to a less restrictive stance:

"The recession in economic activity intensified in most parts of the world during 1982. At the same time, however, further progress in curbing inflation was recorded in several of the major industrial countries. This progress had favorable implications for the real incomes of consumers, and the accompanying decline in interest rates improved business incentives and 
reduced inventory carrying costs. [...]As just noted, monetary conditions in many of the major industrial countries have tended to ease over the past year, in part because unexpectedly low rates of growth of nominal gross national product have caused the established objectives for the growth of monetary and credit aggregates to become less restrictive. [...] By early 1983, the better outlook for inflation appeared to have improved confidence sufficiently to set the stage for an upswing in production and trade. Indeed, signs of such an upswing were already evident in a number of industrial countries, and especially in the United States" (IMF annual report, 1983, p. 1-3).

\section{9) Peak: 1984 Q2 ; Trough: 1986 Q4}

IMF reports identified a downturn that started in the second half of 1984 and reached its trough in late 1986/early 1987. The timing of recession was however uneven across countries. US monetary policy, which had turned more and more from late 1983 was the first factor leading to the global slowdown in output growth:

"The overall pace of economic activity in industrial countries moderated in 1985, after the strong expansion recorded in 1984. The slowing was largely attributable to a sharp deceleration of growth in the United States. The pace of expansion also dropped back slightly in Canada and Japan, while it remained little changed in Europe." (IMF annual report, 1986, p. 1).

US increase in interest rates and subsequent appreciation of the dollar put significant pressure on many countries. Such troubles led to the Plaza agreement in September 1985. The depreciation of the dollar following this agreement decreased Japanese exports in 1986.

"An asymmetry in the responses to the substantial exchange rate changes that occurred between the first quarter of 1985 and the first quarter of 1987 also contributed to the slowdown, with growth weakening more quickly in countries with appreciating currencies than it strengthened in those with depreciating currencies. These asymmetries in the adjustments to both types of relative price changes appear to have exerted a dampening impact on demand and activity in the short run." (IMF annual report, 1987, p. 1-3).

According to the IMF, protectionist measures implemented in 1986 as a consequence of moderate growth had also worsened the development of world trade and output growth:

"At the same time, the slowdown in industrial countries, particularly in the United States, was sharper than expected, world trade was sluggish, protectionist pressures intensified, real primary commodity prices declined steeply, and the developing world experienced a setback in its efforts to achieve growth with adjustment. (IMF annual report, 1987, p. 1) 
Thus, during this recession, the lead of the United States, as well as exchange rates and terms of trade played a prominent role. Their role was also crucial in the recovery that started in 1987:

"Following a slowdown in 1986, output growth in the industrial countries as a group strengthened significantly in 1987. [...] The growth performance was somewhat better than had been expected at the beginning of the year as the positive effects of the large terms of trade and exchange rate changes in 1985-86 gradually outweighed their mainly negative short-run impact. This lag pattern can be attributed to asymmetric responses of losers and gainers from the large changes in competitiveness and relative prices, with the former adjusting considerably faster than the latter." (IMF annual report, 1987, p. 9).

\section{0) Peak: $1988 Q 4$; Trough: $1993 Q 2$}

The recovery continued throughout 1987, sustained by "the strength of stock markets during the current business cycle and especially during most of 1987, which added substantially to household wealth" as well as by "policy action, particularly the fiscal package adopted in Japan in May 1987." (IMF annual report, 1987, p. 9). Growth intensified in 1988, despite the global stock market crash of October 1987, which did not affect output substantially. It reached a peak in the last quarter of 1988, and cooled down afterwards, although the slowdown was less pronounced in Europe:

"On the domestic front, output growth in industrial countries exceeded expectations, but inflation was up a little. Tighter monetary policies were associated with a rise in interest rates; progress toward fiscal balance was generally modest. Developing countries as a group experienced one of their highest rates of growth in the past decade, mostly because of buoyant exports of manufactures by Asian economies.[...] Toward the end of 1988 and in early 1989, growth in North America, Japan, and the United Kingdom slowed to rates more in line with estimates of potential growth, but in continental Europe, the momentum of economic activity continued. Economic activity in 1988 was stronger than most observers expected, partly because the stock market decline in late 1987 had less serious deflationary effects on demand than initially feared." (IMF annual report, 1989, p. 1).

The downward cycle continued in 1989 and 1990 because of restrictive monetary policies and - starting early 1990 - because of an increase in oil prices and political uncertainty caused by the war in Kuwait. There were however significant differences in countries' growth during these period since a part of Western Europe (mainly Germany) was still disconnecting from the rest of the world, because of the political process ongoing in this region. 
"Growth in the European Community in 1989 was also influenced by the process of integration, and particularly by the scheduled completion of the single market in 1992, which boosted investment in anticipation of expanding markets and greater competition." (IMF annual report, 1990, p. 1).

"The slowdown reflected mainly the recession that began during the year in North America and the United Kingdom and slower growth in a number of European countries, which offset considerably stronger growth in Japan and West Germany. The slowdown in 1990 can be attributed to several factors, including the lagged effect of a tightening of monetary policy in North America and the United Kingdom, the temporary rise in oil prices, and increased uncertainty related in large measure to the conflict in the Middle East and to oil market developments. [...]The slowdown that had started in mid-1989 in the United States became more pronounced in the second half of 1990." (IMF annual report, 1991, p. 3).

In 1991, the slowdown turned global, reinforced by political difficulties in the Middle East and Eastern Europe:

"Overall world economic growth declined slightly in 1991, owing to reductions in output in a number of industrial countries, the sharp drop in output in Eastern Europe and the former U.S.S.R., and stagnation in the Middle East following the conflict in that region." (IMF annual report, 1992, p. 1).

Whereas North America and United Kingdom lagged behind continental Europe and Japan in 1990 and 1991, the situation reversed in 1992, when the latter experienced (weak) recovery. The growth path of emerging markets remained also uneven:

"This modest growth [in 1992] was marked by a weak recovery in the industrial countries, a further weakening of growth in many developing countries in Africa, and further substantial output losses in the countries in transition to a market economy. In contrast, the developing countries in the Middle East and Asia experienced stronger growth in 1992, as did many countries in the Western Hemisphere. [...] Although the United States and Canada emerged from recession, growth declined sharply in Japan and many countries in Europe because of depressed levels of consumer and business confidence and because of actions by households and businesses to reduce excessive levels of debt following the sharp declines in asset prices. Economic activity in Europe was also restrained by persistently high short-term real interest rates and considerable tensions in exchange markets." (IMF annual report, 1993, p. 3).

In early 1993, the world went out of the recession, pulled by the expansion of North America, while Japan was still trapped in deflation and Western Europe was still experiencing difficulties related to restrictive monetary policies in the wake of current account imbalances and the German reunification: 
"In early 1993, the expansion in North America became more deeply rooted and the U.K. industrial sector showed encouraging signs of recovery following reductions in interest rates and the depreciation of sterling. [...] In Western Germany, economic growth declined sharply, reflecting, in part, high interest rates associated with tight monetary policies required to contain inflation and expansionary fiscal policies following unification. "IMF annual report, 1993, p. 3).

In Europe, these difficulties started to vanish in the second half of 1993, after the exchange rate crisis:

"Following considerable turbulence within the European Monetary System (EMS) from mid1992 through July 1993, tensions abated significantly after the widening of the exchange rate mechanism (ERM) intervention band in August 1993." Then, "monetary conditions were eased gradually in 1993 and early 1994", setting the path for recovery (IMF annual report, 1994, p. 1).

Overall, the 1989-1993 recession was long but characterized by very different timing of slowdown and recoveries across countries.

\section{1) Peak: 1994 Q4 ; Trough: 1995 Q4}

After continuous global expansion that peaked in 1994 Q4, there was a sudden slowdown in 1995 , partly caused by restrictive monetary policy implemented to curb inflation pressures in advanced economies and by the transmission of the Mexican crisis to the US and emerging markets:

"For some countries at relatively advanced stages of recovery-including Australia, New Zealand, the United Kingdom, and the United States-the slowing of growth in 1995 represented a necessary moderation from rates of expansion higher than capacity growth and followed monetary tightening intended to prevent the buildup of inflationary pressures. The United States saw a marked slowdown of growth in the first half of the year, owing to a sharp inventory correction and a decline in real net exports that reflected the effects of the recession in Mexico. Growth rebounded strongly in the third quarter, owing to the continued strength of investment and a pause in inventory adjustment, but then slowed to below. "IMF annual report, 1996, p. 1).

The slowdown of several economies transmitted to Europe through trade and it led countries to implement expansionary policies, as in the United States:

"Strong currencies appeared to have exacerbated the already negative effects on aggregate demand of weak consumer and business confidence. In response to the slowdown, monetary 
conditions in most European countries were eased in late 1995 and early 1996." (IMF annual report, 1996, p. 1).

In 1996, the effects of the Mexican crisis were vanishing and expansionary monetary policies pushed the world into recovery:

"Activity picked up in a number of industrial countries, while growth resumed in those developing countries in the Western Hemisphere that had been adversely affected by the financial crisis in Mexico in 1995. Growth rates also strengthened in the Middle East and, more markedly, in Africa. In the transition countries as a group, output stabilized after six years of deep decline. "(IMF annual report, 1997, p. 1).

\section{2) Peak: 1998 Q1 ; Trough: 1999 Q1}

The 1997-1998 financial crises in Asia hit prominently emerging markets and Japan. On the contrary, North America and Europe first benefited from Asian financial troubles despite the transmission of the crisis through trade:

"The redirection of financial flows toward the mature markets following the onset of the crisis, together with prospects for lower inflation, contributed to significant declines in medium- and long-term interest rates in the industrial countries in late 1997 and early 1998-in some cases to 50-year lows. This easing of financial conditions, particularly in North America and in Western Europe, contributed, in turn, to further gains in equity markets, with many indices reaching new peaks. These developments helped support the growth of domestic demand in industrial countries at the same time that net exports began to be adversely affected by the Asian crisis." (IMF annual report, 1998, p. 8).

In mid-1998, Japanese authorities implemented fiscal and monetary measure to cope with the recession, and in early 1999, perspectives had clearly improved:

"Among the industrial countries, the recession in Japan deepened during 1998 before a sharp rebound in activity in early 1999, and growth in the European Union (EU) waned during the period, but the expansion in the United States remained remarkably strong. World output growth slowed to 2 percent in 1998 from 4 percent in 1997, with preliminary indications of some pickup in early 1999-although growth appeared to remain significantly weaker than during 1994-97. This fourth global slowdown in a quarter century stemmed mainly from the crises in emerging markets and the Japanese recession. "IMF annual report, 1998, p. 8).

13) Peak: 1999 Q4 (sharp fall starts in 2000 Q4) ; Trough: 2002 Q1 
The expansion of world output and world trade was strong in 1999 and 2000 despite the US slowdown. In other countries, the downward cycle started in 2000 Q4 or early 2001 only, following the US recession, stock markets' decline and the global increase in oil prices:

"Following a period of economic growth at or above potential, activity in the advanced economies weakened late in 2000, led by a sharp slowdown in the United States, stalling recovery in Japan, and moderating growth in Europe. Economic expansion in the United States slowed sharply during the rest of the year [second half of 2000]. This slowdown was a result, in part, of the tightening of monetary policy during the year, and also of higher oil prices and the decline in equity markets, including a sharp fall in the NASDAQ. Weighed down by low consumer confidence, slowing business investment, and weakening external demand, economic growth in Japan failed to sustain the strong performance of the first quarter. [...] In Europe growth eased during the latter part of 2000 and in early 2001 apparently in response to the impact of higher oil prices on purchasing power, weaker business confidence, and spillover effects of the U.S. slowdown." (IMF annual report, 2001, p. 1).

In 2001, the same factors pushed the world further into a global recession, which was aggravated by the attacks of September 11, 2001. In the early 2002, mostly because of the easing of monetary policy, the change in the cycle became noticeable. Overall, the timing of this short cycle had been more synchronized than the ones of the previous cycle since the mid-1980s (in 2002, Japan stood as an exception):

"In 2001 the world economy experienced a synchronized, widespread slowdown after the unusually strong expansion of the previous year, with growth slowing in every major region except Africa. The slowdown reflected a series of intertwined developments in 2001, including the downward adjustment in equity prices (particularly in the information technology sector), a rise in energy prices, and the tightening of monetary policy in industrial countries in response to evidence of rising demand pressures. The already weakening international economy was further affected by the September 11 terrorist attacks in the United States, which had a substantial-although largely temporary-influence on macroeconomic conditions. In the first few months of 2002, however, there were increasing signs that the slowdown was bottoming out in most regions and that growth was turning up in some-most notably North America and a number of east Asian countries. This reflected, at least in part, the significant easing of macroeconomic policies in the advanced countries in 2001, especially in the United States and in a number of emerging countries in Asia, as well as the completion of ongoing inventory cycles. Partly mirroring the weakening of growth in 2001, inflation remained extremely low almost everywhere. Indeed, ongoing deflation in Japan continued to worsen already difficult economic condition. "(IMF annual report, 2002, p. 1). 


\section{4) Peak: 2006 Q1 ; Trough: 2009 Q2}

Before the financial turmoil of 2007, the steady expansion that followed the 2002 recovery had leveled off in the United States in early 2006 - as well as in some other countries -, mostly because of the stagnation of residential investment growth and exports:

"Growth in United States slowed markedly, declining from an annual rate of 21/2 percent in the second half of 2006 to 0.6 percent in the first quarter of 2007, primarily because of declines in net exports, inventories, and residential investment. "(IMF annual report, 2007, p. 9).

Slowdown in growth led to turmoil in the US financial system (prominently in housing finance), which spread rapidly to the rest of the world in 2007 through financial markets:

"Spillovers from the credit deterioration in the U.S. subprime mortgage market led to a fullblown liquidity crisis in term-funding interbank markets in August 2007." (IMF annual report, 2008, p. 14).

As the US financial crisis worsened in autumn 2008, it transmitted to the rest of the world through various channels:

"The past year has been a roller coaster for the global economy. The severe financial crisis that followed the collapse of Lehman Brothers in September 2008 had a significant negative effect on the world economy, with global output falling by 1/2 percent in 2009. Advanced economies were the most significantly affected by the financial crisis, having to deal with a serious credit crunch, battered balance sheets, and rising unemployment. In these countries, output fell by 31/4 percent in 2009. The crisis was transmitted swiftly across the globe through a number of channels-including a collapse in trade, a drying up of capital flows, and a drop in remittances. When the dust had settled, it became obvious that several emerging markets and low-income countries had been severely affected by the global crisis, the worst in over 60 years. " (IMF annual report 2010, p. 16)

The global recovery in the second semester was due to the reaction of monetary and fiscal policies which engaged in strong expansionary stimulus all over the world in 2009:

"Policymakers responded to the crisis by implementing a set of bold and aggressive measures delivered in an environment of unprecedented cooperation. In monetary policy, countries pushed interest rates toward zero and embarked on unconventional measures. Central banks cooperated, with coordinated interest rate cuts and swap lines. In fiscal policy, countries adopted a countercyclical stance, accommodating the recession-induced increase in deficits and complementing it with a fiscal stimulus. All in all, major advanced 
economies and emerging markets delivered a 2 percent of GDP fiscal stimulus in 2009, and much of the gain came from the very act of coordination. Countries also put measures in place to support the financial system, including asset purchases, capital injections, and various types of guarantees. These measures paid off. A recovery began to emerge in the second half of 2009 and gained steam in early 2010, although increased financial market volatility in May 2010 once again raised some questions about the recovery's durability." (IMF annual report 2010, p. 16)

\section{5) Peak: 2010 Q2 ; Trough: 2013 Q1}

The 2009 recovery did not last long and the world economy quickly stalled after reaching a peak in $2010 \mathrm{Q} 2$ :

"During the second half [of 2010], as the inventory cycle leveled off and fiscal consolidation loomed in many advanced economies, fears of a double-dip recession increased. (IMF annual report 2011, p. 12)"

The public debt crisis in Europe contributed further to the new recession. A partial recovery only started in 2013, after several policy actions had been taken:

"Policy actions helped stabilize the global economy. The United States has adopted a budget and debt ceiling extension, and a strengthening economy has set the stage for normalization of monetary policy. These steps removed important uncertainties that were clouding the outlook in October 2013. In Europe, greatly reduced tail risks due to the implementation of policies at the national and regional levels and the return of growth in almost all countries led to substantial improvements in market confidence in both sovereigns and banks. In Japan, "Abenomics" was making a good start as deflationary pressures were abating and confidence was rising. And emerging market economies, after having experienced several bouts of volatility, were adjusting policies in the right direction." "(IMF annual report 2014, p. 14) 